\title{
EL PROCESO CONSTITUYENTE Y LA VIOLENCIA POLÍTICA: LOS DEBATES CONSTITUCIONALES DE 1979 Y 1993 FRENTE A LA SUBVERSIÓN
}

\section{THE CONSTITUENT PROCESS AND POLITICAL VIOLENCE: THE CONSTITUTIONAL DEBATES OF 1979 AND 1993 AGAINST SUBVERSION}

\author{
Galimberty R. Ponce Flores ${ }^{(1)}$ \\ Universidad Nacional del Altiplano, Perú
}

\begin{abstract}
Resumen: Este trabajo evalúa la capacidad deliberativa de los procesos constituyentes de 1979 y 1993. Adicionalmente, examina el lugar que le correspondió ocupar al fenómeno de la violencia política en dichos procesos. En ese orden, se puede advertir que la Constitución de 1979 no abordó el problema de la violencia política, y tampoco lo hizo la Constitución de 1993, más bien buscó soluciones punitivas para enfrentarlo, además que esta última tuvo origen antidemocrático. El proceso constituyente como un espacio de articulación, expresión y participación pública democrática quedó frustrado porque ni la Constitución de 1979 y ni la de 1993 abordaron el factor de la violencia política en el debate y discusión constitucional.
\end{abstract}

Palabras clave: Constitución, Deliberación Pública, Violencia Política, Proceso Constituyente.

\begin{abstract}
This paper evaluates the deliberative capacity of the constituent processes of 1979 and 1993. In addition, it examines the place that corresponded to the phenomenon of political violence in these processes. In that order, it can be noticed that the Constitution of 1979 did not address the problem of political violence, and neither did the 1993 Constitution, rather them looked for punitive solutions to face it, in addition the latter had an undemocratic origin. The constituent process as a space of articulation, expression and democratic public participation was frustrated because neither the 1979 Constitution nor the 1993 one addressed the political violence factor in the debate and constitutional discussion.
\end{abstract}

(1) Abogado por la Universidad Nacional del Altiplano de Puno. Con estudios concluidos en de maestría de Derecho Constitucional y Procesal Constitucional por la misma casa de estudios. Correo: galimberty@gmail.com 
Keywords: Constitution, Public Deliberation, Political Violence, Constituent Process. 


\section{Introducción}

La violencia política en el Perú se originó después de la segunda mitad del siglo $\mathrm{XX}$, teniendo como actores y protagonistas centrales a Sendero Luminoso (en lo sucesivo, SL) y el Movimiento Revolucionario Túpac Amaru (en lo posterior, MRTA). La tragedia que causaron estos grupos subversivos atentó contra los derechos humanos, la democracia, la paz social y el orden estatal. Sus acciones tuvieron como característica común el uso de la violencia para lograr sus fines, ambas organizaciones crearon un contexto de pánico y amilanamiento social en la colectividad (la población peruana). La violencia y el miedo se extendieron por más de dos décadas.

Desde el Estado, con el afán de combatir y aplacar el terrorismo, se adoptaron medidas y políticas de carácter extraordinario, principalmente mediante las fuerzas del orden como policías, militares $y$, al mismo tiempo, utilizando medidas constitucionales de carácter extraordinario como el estado de emergencia o de sitio. Tales acciones con el paso del tiempo, no sirvieron únicamente para disminuir y abatir a los grupos subversivos, sino que también tuvieron repercusión en la población civil que resultó afectada por estar, prácticamente, en medio de las acciones desarrolladas tanto por las fuerzas del orden público como los miembros del orden subversivo.

Quizás resulte un poco difícil precisar con exactitud el origen de la violencia política en el Perú, sin embargo, tentativamente se remonta hacia a fines de 1960, y adquiere relevancia o notoriedad en la década de 1980. Todo este proceso supuso, en esencia, que el factor violencia (Gonzales, 1988, p. 19) con el devenir del tiempo fuese incrementándose, a su vez, implicó que la acción subversiva se hiciera más visible, llegando a exhibirse en casi todos los planos de la sociedad peruana, inclusive, a "poner en jaque al país y descubrir una democracia inerme ante su brutal acoso" (Tello, 1989, p. 31). Mientras el escenario de violencia se ponía al descubierto y alcanzaba sus máximas manifestaciones, se produjeron diversos eventos o situaciones paralelas, tales como la inflación económica, la pobreza (subempleo y desempleo) ${ }^{(2)}$, analfabetismo, mortalidad infantil, instalación de un gobierno autoritario y otros. Adicionalmente, en el mismo periodo aparece en la escena política y jurídica nacional la discusión, redacción y aprobación de las constituciones de 1979 y 1993. Estos hechos, en cierta forma, fueron el caldo de cultivo para avivar más la lucha armada y sirvieron como respaldo a las acciones iniciadas por Sendero Luminoso, que creía que las situaciones críticas requerían de soluciones radicales.

(2) Los años que van de 1975 a 1990 en términos económicos significó la "inestabilidad monetaria, precios distorsionados, caída de la producción y quiebras" (Webb, 1999, p. 24), además, la caída del PBI es notable porque el Estado cada vez dejó de participar en las decisiones económicas, tal es así que la reducción del indicador del Producto Bruto Interno decrece del 18.9\% al $8.5 \%$ en el lapso de 15 años. En dicho ambiente económico la violencia política fue creciendo de forma progresiva. 
Los momentos estelares que marcaron y, en cierta medida, caracterizaron la segunda mitad del siglo XX en el Perú, desde la perspectiva de la historia política y constitucional, son la discusión, redacción y aprobación de dos nuevos textos constitucionales (1979 y 1993) ${ }^{(3)}$. Estas cartas constitucionales traen consigo y ponen en marcha un nuevo programa constitucional que tiene la consigna de limitar las cuotas de poder fáctico y político, a la vez que, garantizar la estabilidad democrática. Además, estos dos eventos o momentos constitucionales supusieron la activación de la Asamblea o Congreso Constituyente ${ }^{(4)}$. Para que la regulación jurídico-constitucional resultara democrática y legítima, los objetivos planteados fueron: (i) garantizar la participación e inclusión de todos los agentes o grupos sociales afectados por la decisión constitucional ${ }^{(5)}$, y, (ii) lograr consenso popular sobre los aspectos más acuciantes y urticantes para la sociedad peruana.

La implantación de un nuevo orden constitucional, es decir, la creación o génesis de una nueva Constitución, casi siempre grafica la renovación de la organización del poder público (el Estado), la ampliación de los objetivos políticos, la búsqueda de la integración política y cultural, así como la realización de los derechos (concretización de la libertad, igualdad y solidaridad). También, queda como cierto que el proceso constituyente representa la democratización o ampliación de la capacidad democrática de la Constitución, todo momento de creación de la Constitución es una oportunidad para dinamizar y afirmar la democracia.

En ese sentido, en el presente trabajo analizamos desde la dimensión constitucional la violencia política, porque al inicio y casi a la culminación de este periodo marcado por acciones subversivas se gestaron nuevas constituciones ${ }^{(6)}$. El proceso constituyente -probablemente- es una herramienta que pudo servir para afrontar momentos de tensión política e ideológica muy fuertes como las ocasionadas por SL y MRTA. ${ }^{(7)}$

(3) Queda resaltar que mientras la violencia política se desarrollaba y ganaba auge, la redacción y expedición de estas dos constituciones tuvieron lugar en el país, entonces, esto conlleva a estudiar la relación, el factor de convergencia o la importancia de una Constitución frente a la movilización de la violencia política.

(4) Es menester indicar que dentro de la teoría constitucional la elaboración o redacción de nueva Constitución, casi siempre, representa innovación y modificación de las circunstancias políticas, sociales, culturales, económicas y jurídicas, es decir, la presencia de factores estructurales cuestionan la legitimidad del orden constitucional vigente. En ese orden, para recuperar la confianza constitucional se acude a la Asamblea o Congreso Constituyente porque son los medios a través del cual la colectividad delibera de forma democrática en la esfera pública.

(5) La elaboración de un texto constitucional es producto del ejercicio pleno de la democracia, en ese sentido, busca incorporar e incluir al debate constitucional a todos los grupos que demandan atención y exigen la transformación del orden estatal y constitucional vigente.

(6) El proceso de discusión y aprobación de los textos constitucionales de 1979 y 1993 estuvieron marcados por la presencia de la violencia política (conflicto armado interno, guerra civil interna o terrorismo), de esta manera queda justificado prestar atención al lugar o espacio que ocupó dentro de la discusión constitucional en el país.

(7) Estamos conscientes que la utilidad del proceso constituyente como espacio de deliberación y 
En síntesis, los aspectos que se abordaremos son: (i) el proceso de creación constitucional (¿Cómo se origina una Constitución?), (ii) la precisión liminar sobre los orígenes del terrorismo o la violencia política en el país, (iii) las probabilidades e improbabilidades de la Constitución frente a la violencia política (¿qué puede hacer y qué no puede hacer frente a la violencia?), (iv) la posición de la violencia política en la discusión, redacción y aprobación de los textos constitucionales de 1979 y 1993, y, (v) la deliberación necesaria para fundar textos constitucionales democráticos. En tal orden, principalmente, el objetivo de este trabajo es desarrollar dos asuntos importantes: (i) la posición de la violencia política en los debates constitucionales de 1979 y 1993, además, (ii) darcuenta dela cantidad de deliberación necesaria parafundar textos constitucionales democráticos. En este último caso, será analizada con énfasis la violencia política y su tratamiento realizado en el seno del proceso de creación constitucional. Asimismo, la organización del texto se presenta siguiendo este esquema. ${ }^{(\mathbf{8})}$

\section{Génesis e implicancias de la Constitución}

En la actualidad no existe disputa en que la Constitución es una norma que articula un conjunto de principios y valores, además que, al mismo tiempo, acoge derechos individuales y organiza el poder. En estas ideas descansa la noción mínima o atómica de Constitución. También, una dimensión importante de un texto constitucional es su origen o creación, en otros términos, la parte sustancial o densa de la noción de Constitución se va a configurar y moldear de acuerdo a la intención y voluntad constitucional inicial, lo que equivale a decir que el texto constitucional se orientará a atender las razones, motivos e intereses de la colectividad. Los momentos más importantes por los cuales a traviesa una Constitución son su creación, su puesta en vigencia y su extinción, es así que importa mucho su origen porque en él se podrá encontrar la filosofía que la inspira, el contexto en que surge, su tiempo estimado de duración y la legitimidad que ostenta. Este aspecto, en el presente trabajo, es el que más nos interesa, es decir, el origen de la Constitución.

En relación al origen o génesis de la Constitución, con términos sencillos podemos indicar que responde a la necesidad de cambio existente en la sociedad, así como a la intención de la colectividad de instituir un nuevo orden constitucional. Entre los factores decisivos para realizar modificación total de la Constitución (o creación de uno nuevo) encontramos: (i) el descontento social y la propuesta de modificación de la estructura constitucional como remedio para

democratización dependerá de la voluntad política así como las acciones que emprendan los actores políticos, al menos, aquellos que estén vinculados con el proceso mismo. Al respecto, en el trabajo se podrá constatar cuál ha sido el rol y como es que fue usado dicho proceso frente a la violencia política.

(8) En este trabajo nos focalizamos en analizar el factor violencia política, sin embargo, es evidente que existen varios aspectos que quedan fuera del debate constitucional de los años 1979 y 1993 , el mismo que será objeto de otro tipo de estudio. Es más, no solamente quedó fuera del discurso constitucional el factor violencia política, sino que hubieron otros más como son: los derechos, la organización democrática del poder, entre otros. 
atenderlo; (ii) el distanciamiento entre las normas constitucionales y la realidad política-social; (iii) las fallas de la Constitución en la regulación del poder; (iv) la crisis y tensión social insostenibles; (v) la pérdida de legitimidad de las normas constitucionales; (vi) la erosión del sistema de gobierno vigente, entre otros. Este elenco de situaciones da como resultado, en muchas ocasiones, la fundación de un nuevo orden constitucional. También, el proceso de génesis de un nuevo texto constitucional tiene fuerte componente popular, es decir, la población se involucra de manera amplia en el proceso constituyente, ello en aras de lograr consenso sobre la cuestión pública, la organización y distribución del poder, la garantía de los derechos y, al mismo tiempo, establecer la filosofía, así como los valores que conducirán a la sociedad. En ese orden, queda claro que todos o la mayor cantidad de ciudadanos, provenientes de todos los sectores, deben legitimar el contenido de la Constitución, solo así ostentará vocación democrática.

La cuestión central del proceso constituyente o momento de creación constitucional es la legitimación del producto, es decir, la Constitución. Un texto constitucional, esencialmente, es resultado del involucramiento de los diversos sectores sociales y culturales porque el proceso de génesis constitucional es un espacio amplio de convergencia y divergencia política, ideológica y cultural, además, la sociedad civil y los colectivos de diversos sectores se reúnen para deliberar y revestir de legitimidad a la decisión constitucional final. Así, queda prohibida la exclusión de individuos y grupos de la ciudadanía interesados en expresar y dejar constancia de sus demandas ${ }^{(9)}$. En suma, la Constitución es producto de la concurrencia de los procesos sociales, culturales, políticos e ideológicos, entonces, solo de esta manera quedará garantizada y legitimada el pacto constitucional (voluntad final) ${ }^{(\mathbf{1 0})}$; al respecto, Zagrebelsky (2008, p. 334) sostiene que la Constitución debe tener la "capacidad de salir del área del poder y de las frías palabras de un texto escrito para dejarse atraer a la esfera vital de las convicciones y de las ideas queridas, sin las cuales no se puede vivir y a las que se adhiere el calor".

En ese orden, la noción de Constitución implica diversas formas de entender la organización jurídica y política de un país, en tal sentido, podemos considerarla del siguiente modo: (i) como "sistema de reglas, sustanciales y formales, que tiene como destinatarios propios a los titulares del poder", además, recoge aquellas "perspectivas de transformación del derecho mismo en dirección de la igualdad" así como la protección de los derechos fundamentales en general (Ferrajoli, 2009,

(9) Nótese que la redacción de nuevo texto constitucional, esencialmente, implica un proceso participativo porque las diversas propuestas que emergen de la sociedad civil y la colectividad en general, tiene que reflejarse en la voluntad constitucional final, esto es, cuando nueva Constitución entra en vigencia.

(10) La concurrencia de diversas voces e ideas dan como resultado que la aprobación del texto constitucional sea resultado y reflejo de proceso de deliberación profunda, ya que todos los sectores de la población tienen que encontrar un lugar que atienda sus demandas y necesidades. 
p. 439); (ii) es producto de rupturas revolucionarias y de pactos fundadores o refundadores de la convivencia civil (Ferrajoli, 2009, p. 441); (iii) establece un orden, asegura la estabilidad de la dinámica política, regula los procesos de integración y formación de unidad, además, se constituye en el "orden jurídico básico de los diversos sectores de la vida social y política" (De Otto, 2010, pp. 36 y 45); (iv) configura y ordena los poderes del Estado por ella construidos, establece los límites del ejercicio del poder y el ámbito de libertades y derechos fundamentales, así como los objetivos positivos y las prestaciones que el poder debe de cumplir en beneficio de la comunidad, además, "la Constitución jurídica transforma el poder desnudo en legítimo poder jurídico" (García, 1991, p. 49); (v) comprende mejor el "orden político", a su vez, implica "racionalizar" el mismo (Aragón, 2013, p. 172; Burdeau, 2002, p. 99), además, recoge "los principios fundamentales que caracterizan [el régimen político republicano] y le da una precisa identidad en el plano histórico-constitucional" (Fioravanti, 2004, p. 38), y, (vi) está caracterizada "sustancialmente por hacer visible una consolidación democrática, asegurando una convivencia social pacífica mediante la exclusión de la violencia para el logro de objetivos políticos, estableciendo el marco institucional para una actividad estatal unificadora, y realizando una libertad, igualdad y solidaridad concretas" (Schneider, 1991, p. 40).

\section{Orígenes de la violencia política: un acercamiento liminar a sus principales momentos}

El origen de la violencia política se data al 17 de mayo de 1980 en la comunidad ayacuchana de Chuschi (Manrique, 2015; Tello, 1989, p. 32)(11). La acción que inició tal proceso es la quema de ánforas electorales en el contexto

(11) En esta fecha, formalmente, inició la Lucha Armada en el país, en especial, "la mañana del 18 de mayo de 1980" (Gonzales, 1999, p. 19), sin embargo, las acciones y operaciones de Sendero Luminoso empezaron muchos años antes, tal es así que podemos encontrar que esta organización formaba parte de las diferentes ramificaciones o divisiones que tuvo el Partido Comunista Peruano en la década de 1960, es más, se menciona que "el grupo más radical -Partido Comunista del Perú-Bandera Roja- sufrió un escisión" de donde surgieron dos grupos "Bandera Roja y Sendero Luminoso" (Pease, 1999, p. 270). Además, la base política e ideológica de Sendero Luminoso se cimienta en Ayacucho, en concreto, durante los años 60 dicha organización operaba en esta parte del país sobre la "base del Partido Comunista Peruano (PCP): el Comité Regional «José Carlos Mariátegui» encabezado desde 1963 por Abimael Guzmán" (Degregori, 2013, p. 19); posteriormente, en 1964 se produce la separación del Partido Comunista Peruano dando paso al surgimiento de dos grupos: i) Partido Comunista del Perú-Patria Roja (PCP- del P-PR), y, ii) Partido Comunista del Perú-Bandera Roja (PCP del P-BR) "ambos de tendencia maoísta". Esta división se produjo como consecuencia de la "concretización de la lucha armada" (Pease \& Romero, 2013, p. 289). En este punto, no está demás considerar que el Partido Comunista Peruano (PCP) tiene diversas ramificaciones, tal como a continuación lo podemos observar: PCP (fundado en 1931), sin embargo, luego de haberse producido la cuarta conferencia en 1963, el mismo que se divide en:

(i) Partido Comunista Peruano (pekineses - 1965):

(a) Saturnino Paredes (1968) y José Sotomayor.

(b) PC del Perú Patria Roja y Bandera Roja (1971: PC del Perú (albaneses) y PC del Perú - Sendero Luminoso - inicia la violencia en 1980).

(ii) PC- Unidad (moscovitas). (Contreras y Cueto, 2004, p. 351). 
de las elecciones nacionales donde participaba por primera vez la población campesina ${ }^{(12)}$. Hay que indicar que el comienzo de la violencia política condensa diversos factores, tales como: (i) la exclusión y marginación social, (ii) la solución de los males sociales a través de la guerra popular, (iii) la aparición de la ideología del marxismo radicalizado y desbocado, y, (iv) la lucha contra la estructura institucional vigente (Estado).

En ese contexto, la eclosión y la participación de Sendero Luminoso en el escenario político y social del país fue mucho más fácil por el clima y la dinámica institucional que abonaron a que el "desajuste del sistema" de gobierno (Lumbreras, 2006, p. 184), la fragmentación y la debilidad institucional se tornaran más visibles ${ }^{(13)}$.

El blanco de ataque de Sendero Luminoso es el Estado y sus diversas dependencias. Los miembros de esta organización buscaban demostrar que el Estado era inoperativo en sus funciones, $y$, asimismo, que era improbable que pudiese atender los males sociales y estructurales de forma eficaz. En la misma línea, empresarios, políticos, representantes religiosos, entre otros, fueron arremetidos porque representaban una extensión del orden institucional y social vigente. Las acciones subversivas realizadas por Sendero Luminoso estaban marcadas por el "pensamiento Gonzalo", y el objetivo central era la destrucción del aparato estatal, de tal modo que los dirigentes asumieran el control del país en todas sus dimensiones (política, cultural, social, institucional, jurídica, económica, entre otras).

En suma, el desarrollo de la lucha armada interna en aproximadamente 12 años de duración, entre 1980 y 1992 causó una gran herida social. Recién en el año

(12) El crecimiento de Sendero Luminoso en los años siguientes fue rápida, ya que durante los años 1980 y 1992 logró expandirse en las regiones de Ayacucho y Apurímac, asimismo, "contó con el respaldo de fracciones importantes de la población rural y urbana" (Bonilla, 2009, p. 129). La acción de este grupo subversivo logró la adhesión de la población campesina, debido a que los males estructurales se iban extendiendo y profundizando cada vez más y resultaba más afectado este sector, y, respecto a los problemas Sendero Luminoso ofrecía salidas simpáticas que guardaba sintonía con ese malestar. Aquí no hay que dejar de mencionar que el sector o grupo social que es más lastimado o afectado por la violencia política es la población pobre de la zona rural o indígena.

(13) Las causas de la aparición de la violencia política o estructural en el país, originada por SL y MRTA, se debe a la injusticia económica, represión política y fenómeno de alienación social (Mansilla, 2000), consecuentemente, cualquier grupo u organización que prometiera la liquidación de dichos problemas recibe apoyo de la población campesina y los sectores urbanos desarraigados (población que permanecía desvinculada de la dinámica del Estado). La ausencia de un "proyecto nacional que aglutinara a los civiles y el surgimiento de la actividad subversiva" (Tello, 1991, p. 31) se dan al mismo tiempo, en tal sentido, quien poseyera mejores recursos para enfrentar dicha situación tendría éxito, ya que el contexto era de anomia y paupérrima organización institucional. A esto se suma la actitud del poder que se muestra "antidemocrática, racista, sexista, fóbica" (Ugarteche, 1999, p. 29), ello debido a que es incapaz de reconocer y manejar adecuadamente la cuestión étnica, social y cultural. Esta situación lo único que logra es alimentar el odio y la indignación popular, lo cual favorece a los intereses de las fuerzas subversivas. 
2003 se obtienen y presentan las cifras oficiales de las víctimas que han sufrido la violencia política, según la Comisión de la Verdad y Reconciliación (CVR) el número de personas que murieron y desparecieron fueron alrededor de 70,000.

\section{Constitución y violencia política: probabilidades e improba- bilidades de la Constitución para aplacar la violencia política}

En líneas precedentes hemos expuesto sucintamente sobre el origen de la Constitución y el surgimiento de la violencia política en el país; ahora interesa dar cuenta de las acciones que se pueden emprender desde el plano constitucional para aplacar situaciones de extrema tensión social, en específico, la violencia política. En tal sentido, la cuestión central de esta parte del texto consiste en responder las siguientes interrogantes: ¿Existen herramientas constitucionales para hacer frente a la violencia política? ¿la Constitución debería ser un arma idónea para luchar contra el terrorismo? ¿los encargados de redactar un texto constitucional deberían prestar atención al fenómeno de la violencia política? ¿tiene algún sentido colocar una cláusula en la Constitución rechazando el terrorismo? ¿cuáles serían las potencialidades de un texto constitucional para combatir o hacer frente al terrorismo? ¿realmente habría algún aporte con que los asuntos vinculados a la violencia política sean tomados en cuenta a nivel constitucional?

Las interrogantes formuladas son difíciles de responder y desbordan los propósito del presente trabajo porque son intrincadas $y$, a la vez, pueden ser respondidas desde diversas aristas, por esa razón, en concreto, lo que nos interesa es plantear las probabilidades e improbabilidades de la Constitución, especialmente, del proceso constituyente (momento de creación del texto constitucional) para hacer frente a situaciones sociales y política dramáticas, en este caso, concretamente, todo lo referido a la violencia política. En términos generales, las probabilidades que tiene la Constitución para enfrentar la violencia política son:

(i) Apertura del proceso constituyente al máximo, es decir, extender y desplegar la potencia del proceso constituyente (momento en que empieza a discutirse los asuntos y problemas de la sociedad) para integrar las demandas de todos los sectores de la población.

(ii) Texto constitucional que debe ser visto como producto de un proceso de deliberación y discusión profunda, el mismo que responde a la intervención y participación de los actores sociales que estén dispuestos a plegarse a la voluntad constitucional.

(iii) Deliberación pública entre ciudadanos, esto es, intercambio de razones y argumentos en relación a la cuestión constitucional, lo cual implica tomar en serio las ideas que circulan en el foro público. 
En relación a las improbabilidades de la Constitución para hacer frente a la violencia o el terrorismo, tenemos:

(i) La Constitución en sí misma no es una herramienta que sirva para combatir el terrorismo o la aplacar la violencia política, por tanto, lo único que se puede lograr a través de este medio es que la agenda constitucional sea lo más amplia posible para captar las ideas de los interesados o afectados con la discusión constitucional.

(ii) Es común que los procesos de lucha social y, en concreto, la violencia política posean una agenda de exigencias muy amplia y exigente, por lo cual, es improbable atender a todas ellas mediante el proceso de elaboración de la Constitución.

(iii) Los propósitos de la Constitución están condicionados a que la población y los actores involucrados estén de acuerdo con el contenido del texto constitucional, de lo contrario, mediante proceso constituyente no se podrá hacer efectuar mayores maniobras, en especial, cuando algunos sectores no quieren participar en la discusión constitucional.

En ese sentido, queda claro que la Constitución por sí misma no puede oponerse o dar opciones para mitigar la violencia política, lo que sí puede efectuar es avivar y agrandar la agenda de la discusión constitucional (esto es, dar mayor margen de participación y desenvolvimiento a las diversas posturas políticas, inclusive, discutir las ideas del orden subversivo).

Tras lo explicado sobre las probabilidades e improbabilidades de la Constitución frente a la violencia política, ahora, corresponde mencionar, al menos de forma general, que la violencia política, en esencia, supone: (i) quiebre de la democracia, (ii) vulneración sistemática de los derechos fundamentales y (iii) desestabilización de las instituciones públicas (del Estado). En la historia reciente del país estos han sido los factores concurrentes y habituales.

Un asunto que ha predominado es la arremetida del terrorismo en la esfera pública del Estado, además, las consecuencias dramáticas que ha dejado porque todo el edificio jurídico, así como el marco constitucional y democrático resultaron desestabilizados. Entonces, los denominadores comunes en dicho escenario son la alteración del orden constitucional, la desestabilización de la democracia, el despedazamiento de las instituciones públicas, la perversión de las relaciones de poder y la vulneración sistemática de los derechos fundamentales ${ }^{(\mathbf{1 4})}$.

(14) En líneas generales el terrorismo es la expresión de "un método o un modo de comportamiento" que consiste "en la realización de un acto o una actividad cuyo resultado intencionado es la creación de un estado psicológico de temor generalizado" (Garzón, 2004, p. 179), en efecto, el modo de operar de 
La violencia política es un factor dramático. es un mal que denigra las instituciones, la democracia y la Constitución. En líneas generales, es un agravio y desestabilización del corazón del sistema constitucional. Frente a este conglomerado, ofrecer argumentos o razones constitucionales para disminuir su impacto es un ejercicio necesario, debido a que el momento más tenso y profundo desde la dimensión constitucional es la redacción de un nuevo texto constitucional, entonces, resulta un momento oportuno para gestionar los problemas dentro de la agenda constitucional para que la decisión final (voluntad) resulte democrática.

La violencia política es un hecho que afecta el corazón del sistema constitucional, ya que el ejercicio de la violencia impacta en dos planos notables: los derechos fundamentales y el orden democrático-constitucional. El núcleo sensible de todo texto constitucional son los derechos fundamentales y la organización democrática del poder. El terrorismo, normalmente, rompe con todo el caparazón o infraestructura constitucional de un país; por eso, la Constitución como norma y empresa colectiva que se origina de la voluntad popular tiene mecanismos válidos y legítimos para defenderse, así como resistir frente a los embates extremistas. En presencia o ante la aparición de violencia, la Constitución puede activar mecanismos democráticos para contraponerse, siendo uno de ellos la ampliación y despliegue del campo de debate constitucional para cambiar, organizar, incorporar o transformar de modo racional las demandas. En otros términos, el arma de que se sirve la Constitución para oponerse al terrorismo o la insurgencia de grupos subversivos es el proceso constituyente (válvula de escape para brindar solución a las adversidades sociales) ${ }^{(15)}$, ya que es el momento donde se evalúan las principales propuestas y necesidades sociales y existe ánimo de cambiar las circunstancias y condiciones reales profundamente. Por esta razón, se ha advertido del poder que ostenta el proceso constituyente como una forma de solucionar las fracturas y distanciamientos del Estado y el gobierno frente al pueblo, a la vez que es un espacio común para cerrar los desencuentros ideológicos (del tipo radicalismo versus democracia).

Se debe de pensar el proceso constituyente como un espacio para acoplar y discutir las diversas propuestas ideológicas y, especialmente, como un camino para considerar y poner a discusión la agenda política e ideológica de los grupos

os grupos subversivos en el país, tales como SL y MRTA, fue la consecución de temor generalizado en la población, entonces, no se trata «únicamente de atentar contra el gobierno sino contra la democracia como forma de gobierno". Expresan rechazo profundo por las instituciones públicas vigentes porque "persiguen cambios estructurales y se expresa rechazo absoluto por las formas de gobierno y de convivencia social existentes". Es más, lo que los caracteriza es "derrumbar el orden reaccionario imperante y construir el nuevo orden social revolucionario" (Oviedo, 1989, p. 30).

(15) Hay que indicar que el proceso de génesis de nuevo texto constitucional tiene en su seno un momento plenamente democrático, es decir, el proceso constituyente es una manifestación plena de la democracia, debido a que forma parte de los debates y discusiones populares (todas las personas y todos los sectores sociales se ven involucrados). 
subversivos. Así, el proceso de elaboración de una nueva Constitución es un lugar de confrontación ideológica y política, para que en el seno de la discusión se eliminen aquellas propuestas irracionales y antidemocráticas. El fin es demostrar la inviabilidad o la exageración del programa político y de gobierno de los grupos subversivos. Al respecto, en el país, en las dos ocasiones que se redactaron y aprobaron los textos constitucionales de 1979 y 1993, se dieron en circunstancias especiales y excepcionales, tal como lo explicamos más adelante.

\section{La disputa y tensión en el campo democrático: ubicación de la violencia en el marco de los procesos constituyentes}

El libre disenso, la pluralidad de opciones ideológicas, la distribución del poder, la integración social, la participación colectiva en igualdad, entre otros, son parte del campo democrático, al menos, estos son los aspectos que le dan forma. Concretamente, por campo democrático entendemos aquél lugar donde los ciudadanos realizan deliberaciones públicas y colectivas frente a decisiones o situaciones que le atañen (o afecten sus intereses). Adicionalmente, es un espacio de intervención activa de los actores sociales, instituciones y políticos. Entonces, élites económicas, sectores populares, partidos políticos, entre otros, se dan encuentro en dicho campo para discutir sus propuestas y programas muchas veces convergentes y, en algunos, casos opuestas. De esta manera el campo democrático está en tensión y disputa constante porque cada facción o sector de la población tiene la necesidad de que se admita su posición y programa político como válido, inclusive, reclaman el poder del Estado para implementarlo.

Debe quedar trazado que los procesos constituyentes son centros de disputa y tensión democrática, esto es, cada vez que se elabora nuevo texto constitucional, en la mayor medida posible, se busca lograr un ambiente de plena participación y deliberación colectiva, solo así el instrumento denominado Constitución tendrá legitimidad y vocación de perdurabilidad. Teniendo en cuenta ello, los procesos constituyentes de 1979 y 1993 deben ser vistos como potentes campos democráticos, momentos en los que la colectividad delibera de forma libre y logrando consenso sobre los principales puntos que les afecta. Entonces, dichos procesos constituyentes deben aprovechar al máximo tal circunstancia y lograr la articulación y participación social y, a su vez, buscar que la sociedad con posiciones diferentes se integre.

En relación a la violencia política, se debe mencionar que estuvo inmersa en el campo democrático porque estaban en proceso de elaboración dos constituciones en distintos momentos. Tal es así que en la confección de la Constitución de 1979 se observó que las facciones políticas como el APRA, PPC, Izquierda Unida, sociedad civil, entre otros, participaron, adicionalmente, otros se alejaron de la misma como Acción Popular o la izquierda radical, y todos tenían una 
propuesta política que fue planteada y tuvo la posibilidad de ser discutida dentro del campo democrático.

En el caso de la creación de la Constitución de 1993 las organizaciones políticas como Cambio 90, PPC, independientes, entre otros, expresaron sus posiciones en el debate constitucional. Todo esto implica que el campo democrático estuvo muy activo y constante, entonces, normalmente los grupos subversivos de SL y MRTA también debieron pasaron a formar parte del campo democrático, sin embargo, el elemento de ruptura que se produce es que algunos grupos radicales decidieron no participar del proceso constituyente y usaron sus propios medios para disputar dicho campo. En suma, la tensión y disputa del campo democrático se produce en dos frentes: la elaboración de un nuevo texto constitucional (lograr nuevo acuerdo democrático) y la violencia política.

Tenemos que dejar en claro que una forma de manifestación del campo democrático es el proceso de creación o elaboración de nueva Constitución. En tal sentido, los procesos constituyentes que dieron origen a la Constitución de 1979 y 1993 son producto de la tensión y disputa democrática, a pesar de que en el caso de 1993 fue producto de un golpe de Estado ${ }^{(16)}$. También en el campo democrático se ubica la violencia política, sin embargo, las herramientas y las acciones usadas por los grupos alzados en armas para disputarlo fueron ilegítimas y prohibidas porque atentaron directamente contra el régimen democrático, la infraestructura constitucional y el orden institucional, es más, vulneraron derechos fundamentales; con lo cual, el factor violencia política logró desbordar el campo democrático y el mismo proceso constituyente.

Hay que añadir que los procesos constituyentes, como manifestaciones del campo democrático, no lograron canalizar la violencia política, es decir, establecer puentes o crear contextos de diálogo, es más, la posición de los diseñadores constitucionales fue la de declarar como enemigos de la democracia a los grupos subversivos y con ello evitar la discusión de sus ideas y propuestas -tarea que era necesaria porque la democracia estaba en plena acción poniendo toda su potencia deliberativa-.

\subsection{La posición de la violencia política en el proceso de discusión, redacción y expedición del texto constitucional de 1979}

Es menester empezar indicando que los orígenes de la violencia política se remontan a la década de los 60 del siglo pasado, tal como fue expuesto en la primera parte, sin embargo, ganó notoriedad en 1980. En un contexto de turbulencia social, política y económica se convoca a Asamblea Constituyente en el año de 1978 con la finalidad de crear una nueva Constitución, en este caso, la Constitución de 1979. Así, en pleno auge de

(16) En este trabajo evitaremos ahondar sobre el carácter antidemocrático de esta Constitución. 
la crisis social ocasionada por los grupos subversivos se gestó dicho texto constitucional. Además, esta carta fue redactada y aprobada por la Asamblea Constituyente de 1978; el contexto fue durante el proceso de transición hacia la democracia, esto suponía que el Gobierno Revolucionario de la Fuerzas Armadas se abstuviera de participar o interferir en las decisiones democráticas y constitucionales del pueblo.

En la historia constitucional del país, este proceso constituyente y su producto, la Constitución de 1979, son calificados de profundamente democráticos porque habrían garantizado la participación robusta de diversos sectores sociales y partidos políticos ${ }^{(17)}$, de este modo fue una expresión auténtica de las fuerzas políticas e ideológicas del país. Tan es así que las únicas facciones políticas que quedaron fuera de dicho proceso constituyente son aquellos vinculados al Gobierno de facto ${ }^{(\mathbf{1 8})}$, así como el partido Acción Popular presidido por Fernando Belaunde y el "partido maoísta Patria Roja" (Belaunde y Eguiguren, s/f, p. 374) que renunciaron a participar.

En el caso del gobierno militar quedó claro no participaría en la constituyente, para dar paso a la convocatoria de la Asamblea Constituyente, al mismo tiempo, se produce el proceso de transición desembocando en la elección de un gobierno democrático, que asumiría funciones el 28 de julio de 1980. En relación a Acción Popular y la izquierda radical, no quisieron participar por seguir sus ideales políticos "innegociables" y porque veían el proceso constituyente como un espacio de legitimación de la estructura vigente del Estado. En todo esto, un aspecto que resulta hasta cierto punto negativo es que el producto constitucional, esto es, la Constitución de 1979 es producto de "una transacción entre el APRA y el PCC" (Contreras y Cueto, 2004, p. 345).

En estos años, mientras se convoca la Asamblea Constituyente, se presentan los siguientes hechos: (i) se produce la transición democrática y, consecuentemente, el cambio constitucional (también se produce el repliegue del gobierno militar, impulsado por los grupos económicos y sociales); (ii) se da paso hacia la transición democrática, que no fue provocada por los partidos políticos, más bien lo hicieron las "organizaciones populares" y "la sociedad civil" manteniendo un rol central debido a la inestabilidad y "debilidad de los partidos políticos" (Degregori, 2014, p. 125), y, (iii) la subversión (SL y MRTA) aparece en la esfera pública ganando mayor

(17) La única organización que no participa en el proceso constituyente es Acción Popular, sin embargo, con normalidad se presenta en las elecciones generales de 1980. También, el sector marxista-radical de izquierda también queda fuera del marco constitucional, es más, el distanciamiento es más notable porque SL "no reconoce vínculos posibles con ningún partido que forme parte de del orden democrático, a pesar de la existencia de grupos maoístas en la Izquierda Unida" (Rubio, 1986, p. 171).

(18) Los factores que han producido la caída del Régimen de las Fuerzas armadas son "la crisis económica, la protesta social y el reclamo del regreso a la democracia" (Contreras y Cueto, 2004, p. 340). En la línea principal de estas acciones estaba comandada por la misma ciudadanía que promovía el cambio en todos los aspectos necesarios, además, los frentes de ataque hacia el gobierno militar provenía tanto del sector político de izquierda así como de derecha, por esta razón, la única opción que les quedó fue la llamada a elecciones "para la formación de una Asamblea Constituyente en 1978" (Contreras y Cueto, 2004, p. 344). 
notoriedad por la radicalidad de sus acciones. Concretamente, dentro de estas condiciones el texto constitucional de 1979 se gestó en un momento de fuerte tensión política y social que minaba el campo democrático. En ese orden, la razón del nuevo texto constitucional, más allá de atender situaciones comunes como el modelo económico, la crisis social e institucional, también, tuvo que enfrentar o elaborar respuestas constitucionales frente al terrorismo.

En lo que sigue tenemos que precisar con cierta exactitud la posición de la violencia política en la deliberación constitucional, a la vez de establecer los puntos flacos o de falla que presentaron. En el caso de PCP-SL, el sector radical del SUTEP, entre otros grupos, quedaron fuera del debate constitucional de 1978 debido a que virtualmente la izquierda extremista se veía excluida del escenario político y jurídico del país Esta posición de insurgencia y apartamiento de la discusión constitucional fue reforzada por los planes políticos de Abimael Guzmán, quien aprovechó la oportunidad para difundir su programa ideológico y político, es más, buscó la adhesión de los sectores marginados y universitarios con vocación de hacer justicia social. Sobre la base de ideas marxistas, leninistas y maoístas Guzmán buscó la articulación del sector académico, así como popular que veían la Asamblea Constituyente como un espacio de dominación y sometimiento, inclusive, que participar en ella hasta podía suponer la rendición; lo cual implicó que su alejamiento del proceso constituyente.

Todo ello suponía en la práctica que la discusión sobre el contenido y tópico de la carta constitucional de 1979 debía prever dos situaciones: i) discusión de las demandas sociales de sectores populares, partidos políticos, entre otros, y, ii) poner a prueba y analizar cada punto del programa político que iba a implementar $\mathrm{SL}$, el MRTA o cualquier otro grupo subversivo.

Es posible advertir aquí que en el sector radical-extremo existía división, ya que los sectores más radicales no aceptaban la idea de la negociación constitucional que implicaba la aprobación de una nueva Constitución, en cambio, el sector flexible-intermedio, de cierto modo aceptaba las condiciones y el modo en que se desarrollaba el debate constitucional dirigido por la Asamblea Constituyente, pero no hubo suficiente voluntad por parte de los constituyentes en tomar en serio este asunto. El momento constituyente desaprovechó la puesta en marcha de un proceso de diálogo y deliberación, tal es así que las acciones insurgentes de Sendero Luminoso se remontan a los años 1977 - 1978, en ese sentido, en la redacción de una nueva Constitución se pudo haber previsto que las personas con tendencias político-ideológicas radicales participasen en la deliberación y discusión de su contenido ${ }^{(19)}$, además, las advertencias sobre la existencia de

(19) Al respecto, el primer gobierno de F. Belaúnde posterga "peligrosa" e innecesariamente "las demandas populares" hecho que acrecentará las desigualdades e insatisfacciones sociales; $y$, frente a Sendero Luminoso adopta una posición militar-represiva (Tuesta, 1985, pp. 24 y 34). Es más, los principales 
grupos subversivos ya "estaban presentes en 1978, y se hicieron cada vez más fuertes" (Heilman, 2018, p. 262). En este punto, las acciones estaban al inicio de todo, es decir, recién empezaban y se desarrollaban.

En el caso concreto de MRTA ${ }^{(\mathbf{2 0})}$ advertimos que se presentan problemas de carácter interno, es decir, de organización, que motivan el distanciamiento de la Asamblea Constituyente de 1978, es así que "Al interior del PSR (Partido Socialista Revolucionario) se precipita la disputa entre los "reformistas" y los "radicales", que conduce a la escisión de dicha organización. Varios miembros de la organización pasan a formar el PSR-ML (Marxista-Leninista), mientras el PSR actúa en la Constituyente y después pasaría a engrosar la federación de grupos de izquierda: Unidad de Izquierda (después Izquierda Unida, IU), que se decide a disputar el poder en el campo democrático" (Oviedo, 1989, p. 108). Esta situación, en cierta medida, tiene impactos directos en la participación posterior que tendrá este grupo en el proceso de discusión constitucional.

En suma, la deliberación constitucional durante casi al final de la década de los 70 se produjo sin prever el factor violencia, es más, cuando revisamos el cuaderno de Debates Constituyentes no encontramos referencias al respecto, es como si el problema no existiera y estuviese ausente del plano político y social del país. Entonces, la posición que ocupó la violencia política en la discusión constitucional -teniendo como referencia los diarios de debates constitucionalesfue muy restringida y casi nula porque no estuvo dentro de la agenda de discusión de los miembros del constituyente.

El ideal democrático exige que el proceso constituyente construya y diseñe una solución constitucional frente al problemas ocasionado por los grupos subversivos, por lo cual, a pesar que ellos hayan renunciado a la discusión constitucional no debía suponer dejar fuera del marco constitucional el asunto de la violencia política. En ese orden, la nueva Constitución creada suponía reformar y transformar las relaciones sociales y la misma organización estatal, por tanto, usar este argumento con la finalidad de convocar a los grupos subversivos para que pudiesen plantear su esquema político en el seno de la Asamblea Constituyente era

\footnotetext{
partidos políticos como son Izquierda Unida y el Apra, de cierto modo, elitizan su participación política porque no logran "engarzar" con el sentimiento y demanda popular. Este ambiente político imposibilita el diálogo y la participación del sector popular, asimismo, disuade la participación de Sendero Luminoso en los diálogos constitucionales y políticos. Entonces, el distanciamiento del sector "radical" se torna visible cuando decide excluirse o "automarginó" del proceso constituyente el PCP-Patria Roja, de este modo dicho proceso iba perdiendo fuerza y legitimidad (Pease, 1981, p. 36). Este escenario fue propiciado por la misma dinámica política y constitucional que en ese momento se dio, al parecer, los constituyentes no tomaron en serio el proceso de elaboración del texto constitucional.

(20) Esta organización cada vez va tornándose más violenta, es así que hacia 1984 "realiza voladuras de instalaciones y atentados y se extiende a Huancayo, Arequipa, Trujillo, Cusco y Chiclayo" (Oviedo, 1984, p. 110). El método que emplea son los coches-bombas y asesinatos en masa, adicional a ello, la proyección ideológica se realiza a través de los siguientes diarios: Voz Rebelde, El diario y Cambio.
} 
una oportunidad para desarticular ideas y razones que predicaban estos grupos, a la vez, hacerles comprender que mediante las herramientas constitucionales y democráticas es posible cambiar las relaciones de poder y la estructura del Estado.

\subsection{La posición de la violencia política en el proceso de discusión, redacción y expedición del texto constitucional de 1993}

El segundo momento constituyente se produjo en 1993, con la característica de que los medios utilizados para la creación o cambio constitucional fueron antidemocráticos, ello debido al golpe de Estado realizado por Alberto Fujimori en alianza con las fuerzas armadas-militares, el 5 de abril de 1992. El Congreso Constituyente Democrático encargado de la redacción de la carta de 1993, estuvo conformado por 80 parlamentarios ${ }^{(21)}$ de diversas filas políticas, sin embargo, con una notable y amplia mayoría de los representantes de Cambio 90-Nueva Mayoría (organización del gobierno), quienes al final pusieron más contenidos en la carta constitucional. Esta situación contrasta con el significado de una constitución que debe implicar un amplio proceso de participación social y política de la población.

El texto constitucional de 1993,tomó distancia y se opuso de manera firme hacia el fenómeno de la violencia política. Mantuvo su propuesta de la pena de muerte por la comisión del delito de terrorismo, lo cual demuestra que la opción planteada y defendida por los constituyentes de 1993 es retribucionista y punitiva, esto es, privilegia el castigo como única forma de solucionar la crisis social originada por los grupos subversivos, entonces, las formas de diálogo o adopción de soluciones democráticas quedaron relegadas.

En los debates constitucionales las alternativas aplaudidas fueron la aplicación de la pena de muerte a los terroristas, así como la imposición de penas severas como la cadena perpetua. Dicho proceso constituyente permaneció cerrado al diálogo sobre el problema de la violencia política tanto a los subversivos, así como a la población. En ningún momento del congreso constituyente se previó la apertura del debate hacia la negociación y acuerdo de paz con quienes se habían

(21) Este hecho antidemocrático viene acompañado del control de las instituciones públicas del Estado, a consecuencia de que "Fujimori y su cúpula cívico-militar quebraron el orden democrático, redactaron ilegalmente el Poder Judicial y los medios de comunicación, persiguieron a sus opositores políticos, constituyeron comandos militares que actuaban al margen de la ley, entre otros delitos contra la democracia y los derechos fundamentales" (Gamio, 2009, p. 38; Burt, 2011; Rénique, 2015). Enfáticamente la década de gobierno liderada por Fujimori no fue calificada de democrática, es así que se considera "el gobierno peruano de la década de 1990 era todo menos democrático", es más, "se trataba de un régimen que había eliminado de hecho la división de poderes, con una mayoría parlamentaria servil y dispuesta a aprobar leyes anticonstitucionales, que dominaba el Poder Judicial y el Ministerio Público y controlaba los medios de comunicación con más impacto social (la televisión y la prensa amarilla) mediante el soborno a sus propietarios" (Arias, 2005, p. 19 - 20). 
alzado en armas ${ }^{(22)}$, entonces, el factor común fue recrudecer e inflar el rango de las penas por el delito de terrorismo, así como garantizar la intervención policial y militar para eliminar la subversión, esta opción primó en los debates constitucionales de $1993^{(23)}$. En ese sentido, la actitud retribucionista y punitiva es la que ganó terreno durante la discusión y redacción del texto constitucional ${ }^{(24)}$. En suma, el momento de creación constitucional de 1993 no sirvió para promover la inclusión y el debate profundo sobre la cuestión de la crisis social, en este caso, la violencia política.

Así, con dicha política adoptada es claro que la agenda de reconciliación y construcción de la paz quedó estancada ${ }^{(25)}$, ya que los miembros del Congreso Constituyente estuvieron más atentos a sancionar la violencia política, mientras el gobierno estaba más preocupado por democratizar su presencia en el poder y menos interesado por cuestiones vinculadas a la violencia política. Con esto queda claro que el nacimiento de la Constitución como un espacio amplio deliberación fue simplemente anulado, es más no hubo esfuerzos suficientes por trabajar los temas recalcitrantes en dicho momento, esto trajo como consecuencia que la deliberación fuese frustrada.

\subsection{Un balance de ambos procesos constituyentes y énfasis en los puntos de quiebre en la discusión constitucional}

En ambos procesos constituyentes observamos que la discusión sobre la

(22) La posición más clara y, en cierto modo, aceptable fue la de Henry Pease García, quien sostenía que el logro de la cultura de paz así como la consolidación de los valores democráticos, no pasa por introducir penas severas para sancionar a los responsables de los crímenes cometidos por Sendero Luminoso; concretamente, indicaba que "la paz es obra de la justicia y no del odio o la venganza". En cambio, la oposición mostró en todo momento que la imposición de la pena de muerte por el delito de terrorismo era el camino más viable, en ese sentido, se insertaron cláusulas constitucionales que sancionen con penas elevadas el delito de terrorismo (Pease, 2001, pp. 2775 y 2776).

(23) Hay que tener presente que el Congreso Constituyente Democrático de 1993, encargado de redactar nueva Constitución, fiscalizar y legislar, estaba compuesto por una mayoría de parlamentarios pertenecientes al fujimorismo, en ese tiempo estaba en el poder el partido político Cambio 90-Nueva Mayoría, por ende, la capacidad de influir y decidir la agenda de discusión constitucional estaba en manos de Alberto Fujimori. Como éste estaba a favor de militarizar la lucha contra el terrorismo no se discutieron opciones alternativas como la pacificación vía acuerdos de paz, teniendo en cuenta que Abimael Guzmán fue captura y pedía diálogo. Cabe indicar que el 12 de setiembre de 1992, aproximadamente, a las 8:40 de la noche la Delta de la Dirección Nacional Contra el Terrorismo (Dincote) comandado por el general Alberto Ketín Vidal Herrera captura a Abimael Guzmán Reynoso, entonces, el máximo líder y cabecillo de Sendero Luminoso fue capturado. Otro cabecilla que es captura por el mismo año es Víctor Polay Campos quién fue líder del Movimiento Revolucionario Túpac Amaru (MRTA). De este modo ambos líderes de organizaciones más temibles fueron puestos a disposición de la justicia, además, hay un claro debilitamiento de dichas fuerzas.

(24) En el seno de la población esta situación de la violencia política también estuvo algo inestable, es decir, no hubo posición clara al respecto, sin embargo, mientras se elaboraba la Constitución de 1993, de algún modo, seguía en pie y vigente la política de la mano dura como"la única respuesta no solo a la violencia terrorista, sino a cualquier problema" (Degregori, 2014, p. 122).

(25) Esta situación, se puede apreciar, al menos en relación con el sector que sí quería ingresar a un escenario democrático. 
cuestión de la violencia política no tuvo la acogida y atención necesaria dentro de la agenda constitucional. Tal es así que, especialmente en el proceso constituyente de 1979, en los debates constituyentes no se hace mención y tampoco se trabaja el factor de la violencia política, e inclusive, un sector radical de la izquierda decide no participar en la misma, con lo cual quedó deslegitimado dicho proceso. En el caso de 1993 la discusión sobre la violencia política en el seno del constituyente se focaliza en adoptar sanciones penales contra los subversivos y la elaboración del texto constitucional se da en un momento de ruptura democrática (golpe de Estado). Entonces, estas particularidades dan cuenta que los procesos constituyentes se han realizado evitando el asunto de la violencia política.

Las actitudes exhibidas en ambos procesos constituyentes son: (i) evitar la discusión del asunto de la violencia política, (ii) expedición de normas penales para

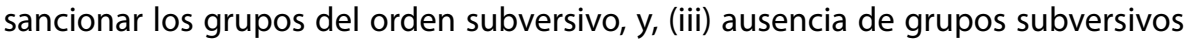
en el debate constitucional (aunque esto se debió en mayor medida a su decisión de no participar).

Las peculiaridades y la naturaleza de los procesos constituyentes -lo que en sí mismo representa- fueron desaprovechadas por las actitudes asumidas por sus congresistas. Tal es así que el asunto de la violencia política no fue tratado seriamente en la dimensión constitucional cuando ello era necesario y urgente porque el país atravesaba un cuadro dramático al enfrentarse a dicho problema que era inminente y real.

En ese orden de cosas, durante el desarrollo de ambos procesos constituyentes, dos situaciones realmente excepcionales entran en colisión o enfrentamiento: democracia (representada por el acto de creación de nueva Constitución) y violencia política (subversión), sin embargo, por falla de la dinámica democrática y el recrudecimiento de las fuerzas subversivas, quedó un hoyo insuperable en los procesos constituyentes en relación a la cuestión de la violencia política, lo cual imposibilitó que el diálogo y consenso.

Tenemos que recordar que la Constitución, ante todo, es una estructura básica que organiza el poder para hacerlo más democrático y legítimo, además, logra hacer confluir diversas fuerzas políticas y sociales, solo en estas circunstancias la deliberación pública podrá ser democrática, de lo contrario, la violencia política y los desacuerdos constitucionales se ahondan.

En ese orden, el quiebre y el desacuerdo constitucional se tornaron crónicos cuando el espíritu de la regulación constitucional recogida en los textos constitucionales en relación a la violencia política fue retributivo y punitivo, ya que solo buscaba sancionar a los culpables. Entonces, la filosofía que inspira a los constituyentes de 1979 y 1993 es que el debate constitucional es inservible para luchar contra el terrorismo, siendo la legislación ordinaria la más capaz para 
solucionar dichos problemas, adicionalmente, la democracia también cae en saco roto porque no existe voluntad para mitigar el proyecto ideológico subversivo en base a los recursos constitucionales y democráticos, sino que se piensa que la eliminación de la violencia política pasa por usar más violencia ${ }^{(26)}$.

Otro asunto que agravó más la situación, en especial, en los inicios de la década de los noventa es la agresión sistemática de derechos por parte del Estado. Este hecho consistió en: (a) el atentado promovido por el Grupo Colina en los Barrios Altos (asesinato de un niño de 8 años de edad) y La Cantuta (la masacre y muerte de 9 estudiantes y un profesor), (b) la detención extrajudicial del General Robles Espinoza por acusar al grupo Colina de graves violaciones a los derechos humanos, (c) prácticas de amedrentamiento contra Mariela Barreto y Leonor La Rosa por acusar al Servicio de Inteligencia Nacional de promover y materializar el atentado contra los derechos humanos de la sociedad civil, y, (d) la muerte de Pedro Huilca Tecse (líder de CGTP), entre otros hechos que ocurrieron a raíz de que el Estado asumiera la lucha contra el terrorismo mediante mecanismos excepcionales. También, se produjo el golpe de Estado del 5 de abril de 1992 -fractura el orden democrático- con el único afán de legitimar el gobierno de Fujimori. En suma, todo esto evidencia que la política asumida por el régimen respecto al terrorismo osciló entre la "indolencia"y "violencia desenfrenada" (Contreras y Cueto, 2004, p. 360) ${ }^{\text {(27). }}$.

En síntesis, la potencialidad de los procesos constituyentes fue desaprovechada porque la capacidad democrática de los mismos no fue considerada en su máxima expresión, al menos, así se exhibió frente al tratamiento de la violencia política. Entonces, el campo democrático que ofrecían dichos procesos constituyentes fue desarticulado y lo que sucedió es que tanto el Estado así como los subversivos adoptaron acciones radicales. Por un lado, el Estado imponía una política de la "irracionalidad" reaccionando con la inflación de la legislación penal -incrementar el rango de años sobre delitos vinculados con el terrorismo-. Las penas o sanciones que proponía son "cadena perpetua" o la aplicación de la figura de "traición a la patria"

(26) En todo esto, también, queda claro que el empleo de políticas estatales represivas contra la subversión fueron denominadores comunes (emplearon mecanismos de excepción constitucional), se manifiestan bien temprano porque se expidieron normas de carácter penal para sancionar a los terroristas convictos, concretamente, en "1981 se dio la primera ley que condenaba a diez o veinte años" (Contreras y Cueto, 2004, p. 352). Los gobiernos de Fernando Belaúnde, Alan García y Alberto Fujimori, en cierta medida, mantuvieron cerrada los canales democráticos y hubo falta de voluntad política para lidiar contra la insurgencia a través de los mecanismos constitucionales.

(27) Inclusive, las propuestas de acuerdo de paz fueron desoídas por el gobierno de Fujimori, además el conjunto de acciones que se implementa son: (i) la instalación de tribunales militares conocidos como "tribunales sin rostro" o "jueces sin rostro" (la acción de estos tribunales era juzgar, pero no se proponía el respeto de los derechos humanos, es más, inocentes fueron condenados por estos), (ii) en 1996 se creó una comisión de revisión de casos que fueron juzgados por terrorismo, esta acción, hacia el año 1999 había progresado en la revisión de $80 \%$ de los casos, de los cuales se liberó a 469 y alrededor de 531 fueron absueltos por el Poder Judicial (Contreras y Cueto, 2004, p. 372). Este tribunal (sin rostro) fue desinstalada en 1997. 
(Contreras y Cueto, 2004, p. 372).También, acudió al uso de mecanismos constitucionales extraordinarios. Por otro lado, las acciones tomadas por los grupos radicales se tornaron más radicales y la violencia fue escalando cada vez más. Todo esto condujo a que el orden democrático y el mismo proceso constituyente fuese destrozado.

\section{La deliberación necesaria para fundar textos constitucionales democráticos ¿Cuánta deliberación era necesaria para garantizar que los textos constitucionales de 1979 y 1993 fuesen redactados en términos democráticos?}

Es difícil establecer la cantidad de deliberación que se requiere para fundar textos constitucionales democráticos, ello debido a que la elaboración de una nueva Constitución supone la concurrencia de diversos factores sociales y políticos. Lo que resulta posible es indicar las condiciones mínimas en que debe desarrollarse el proceso de elaboración de la Constitución. Tal es así que la "deliberación necesaria" para adoptar textos constitucionales democráticos requiere de: (i) presencia y participación de actores sociales y políticos, (ii) lograr consenso sobre los contenidos de la nueva Constitución, (iii) establecer principios comunes que rijan a la sociedad, (iv) desarrollar un esquema de organización del poder que sea democrático, entre otros. En estos puntos debe descansar el debate constitucional a fin de crear textos constitucionales democráticos.

Con el afán de comprender la dinámica de la adopción de textos constitucionales democráticos, debemos analizar si los procesos constituyentes de 1979 y 1993 garantizaron la deliberación pública suficiente dando como resultado la creación de constituciones democráticas. Lo cual supone responder a la interrogante de $i$ si dichos procesos constituyentes han sido lo suficientemente deliberativos para garantizar o fundar constituciones democráticas? La respuesta que podemos ofrecer a dicha interrogante oscila en dos ámbitos: (i) la Constitución de 1979 fue elaborada con la concurrencia de diversas fuerzas políticas y sociales que le dieron cierta legitimidad, sin embargo, no fue lo suficientemente deliberativa porque el asunto de la violencia política no estuvo dentro de la agenda constitucional, y, (ii) la Constitución de 1993 no fue producto de la confluencia de fuerzas democráticas, tampoco contó con la deliberación necesaria sobre cuestiones sociales y mucho menos sobre el tema de la violencia política. Entonces, ambos procesos constituyentes fracasaron en sus intenciones de fundar constituciones democráticas porque no concurrieron los actores sociales y políticos existentes en ese momento, además, en la agenda constitucional no se discutieron temas vinculados con el factor de la violencia política, por tanto, todo esto hizo inviable el consenso constitucional deseado.

La teoría constitucional considera que el proceso de elaboración de un texto constitucional es el momento más democrático que un país puede experimentar, 
es la democracia en acción. La creación constitucional busca establecer. mediante debate profundo y claro, los objetivos comunes que la colectividad desea alcanzar y satisfacer con un nuevo texto constitucional, adicionalmente, establece que la organización del poder sea democrática y que los derechos estén garantizados. La voluntad constitucional significa que es el producto del intercambio de ideas y que todos los posibles afectados o comprometidos en la decisión constitucional tengan la oportunidad de expresar y poner en discusión su propia agenda ideológica y las expectativas jurídicas. Pese a las dificultades que puedan mediar, la deliberación necesaria para fundar textos constitucionales democráticos debe respetar este mínimo de condiciones que se requieren que concurran en el acto de la génesis constitucional.

La deliberación requerida al fundar constituciones democráticas se basa en el consenso y la participación de los actores sociales destacados de una sociedad, además, las reglas de juego del proceso constituyente deben ser claras y transparentes. Entonces, en los debates constitucionales de 1979 y 1993 no participaron todos los sectores de la población peruana, en específico, los grupos que integraron la izquierda radical y aquellos que formaban parte de SL o MRTA fueron renuentes al mismo, adicionalmente, por falta de tino en el seno de los procesos constituyentes no se abordó con claridad y con razones sólidas el asunto de la violencia política. Esto conduce a sostener que no hubo suficiente deliberación para encarar el problema de la violencia política, ya que por un lado no participaron estos grupos $y$, por otro lado, las reglas del proceso constituyente no estaban claras en relación al rol y la forma de abordar el problema de la violencia política.

\section{Conclusiones}

La posición acerca la violencia política en la elaboración y discusión constitucional fue inconsistente. No hubo predisposición abierta para enfrentar el programa político de los subversivos dentro del debate constitucional, es más ni siquiera estuvo en la agenda constitucional del constituyente de 1979, lo mismo sucedió con la Constitución de 1993. Entonces, aquello que se predica en la teoría constitucional, que la génesis de la Constitución es un momento oportuno para articular las divergencias axiológicas, ideológicas y políticas que se suscitan en la sociedad, fue vedado. Mucho más dramático aún es que el debate constitucional (proceso constituyente) no garantizó el ascenso de la racionalidad y el debate sobre las razones que justifican la violencia política y la inviabilidad de sus estrategias para alcanzar el poder.

El proceso de elaboración de una Constitución representa la máxima expresión democrática, Todos los agentes y sectores de la población deberían tener un espacio para expresarse sobre los asuntos que les atañen en el marco 
del proceso constituyente. Sin embargo, en los debates constitucionales de 1979 y 1993 algunos partidos políticos no participaron. Adicionalmente, no se pudo ubicar en la agenda constitucional el asunto de la violencia política -no se discutió sobre sus razones y las implicancias constitucionales que tenían los subversivos-, estos hechos demuestran que la deliberación pública no fue plenamente democrática. Los procesos constituyentes (tanto del 79 y 93) fueron desaprovechados desde la perspectiva constitucional para enfrentar y entender la dinámica de la violencia política. Entonces, la opción que primó entre los diseñadores constitucionales para afrontar la violencia política exhibió un carácter punitivo, es decir, la imposición de sanción penal radical (pena de muerte y cadena perpetua) para desarticular y vencer el terrorismo.

Es incierto establecer la cantidad de deliberación necesaria para que las constituciones resulten democráticas, sin embargo, algunas cualidades que debe poseer un texto constitucional democrático son: garantizar el involucramiento de todos los sectores de la sociedad y organizar el poder en clave democrática, en estos aspectos, mínimamente, descansa el carácter democrático de una Constitución. El proceso de redacción constitucional supone un espacio de discusión y negociación robusta donde los actores políticos, la sociedad civil y el Estado buscan crear un clima de transformación social en beneficio del país, por ende, la deliberación requerida o deseada es aquella donde se presenta la ampliación de los contenidos de la agenda constitucional para abrir las puertas constitucionales a la mayor cantidad de intereses de la población Esto se torna más relevante cuando se constata que las constituciones son producto de las circunstancias, pero su objetivo es permanecer en el tiempo, es decir, muestran vocación de "estabilidad y permanencia" (Bernal, 2018, p. 302).

\section{Referencias bibliográficas}

ARAGÓN REYES, Manuel. (2013). Estudios de derecho constitucional. Madrid: Centro de Estudios Políticos y Constitucionales.

ARIAS QUINCOT, César. (2005). La difícil transición democrática. Lima: Friedrich Ebert Stiftung.

BERNAL PULIDO, Carlos. (2018). Derechos, cambio constitucional y teoría jurídica. Escritos de derecho constitucional y teoría del derecho. Bogotá: Universidad Externado de Colombia.

BONILLA, Heraclio. (2009). La trayectoria del desencanto. El Perú en la segunda mitad del siglo XX. Lima: Fondo Editorial del Pedagógico de San Marcos y Universidad de Ciencias y Humanidades. 
BURDEAU, Georges. (2002). "Una supervivencia: la noción de Constitución". En Revista Peruana de Derecho Público, Administrativo y Constitucional. Año 3, N 4, pp. $91-103$.

BURt, Jo. (2011). Violencia y autoritarismo en el Perú: bajo la sombra de Sendero y la dictadura de Fujimori. Lima: Instituto de Estudios Peruanos y otros.

Congreso Constituyente Democrático. Diario de debates-Debate constitucional de 1993, Tomo V.

CONTRERAS, Carlos, y CUETO, Marcos (2004). Historia del Perú contemporáneo. Lima: Instituto de Estudios Peruanos y otros.

DE OTTO, Ignacio. (2010). Derecho constitucional. Sistema de fuentes. Barcelona: Editorial Ariel S.A.

DEGREGORI, Carlos. (2014). Heridas abiertas derechos esquivos. Derechos humanos, memoria y Comisión de la Verdad y Reconciliación. Lima: Instituto de Estudios Peruanos.

(2013). El surgimiento de Sendero Luminoso. Ayacucho 1969 1979. Lima: Instituto de Estudios Peruanos.

FERRAJOLI, Luigi. (2009). "La democracia constitucional". En Christian Courtis (Compilador), Desde otra mirada. Textos de teoría Crítica del Derecho. Buenos Aires: Eudeba, pp. 431 - 447.

FIORAVANTI, Mauricio. (2004). "Estado y Constitución”, en El Estado moderno en Europa. Instituciones y derecho. Madrid: Editorial Trotta, pp. 13 - 43.

GAMIO, G. (2009). Tiempo de memoria. Reflexiones sobre derechos humanos y justicia transicional. Lima: IDEHPUCP, Instituto Bartolomé de las Casas y Centro de Estudios y Publicaciones.

GARCÍA, Domingo y EGUIGUREN, Francisco. (2008). "La evolución políticoconstitucional del Perú 1976-2005". En Estudios Constitucionales, Año 6, Número 2, pp. $371-398$.

GARCÍA, Eduardo. (1991). La Constitución como norma y el Tribunal Constitucional. Madrid: Editorial Civitas S.A.

GARZÓN VALDÉS, Ernesto. (2004). Calamidades. La responsabilidad humana ante la atrocidad. Madrid: Gesisa.

GONZÁLES MANTILLA, Gorki. (1990). Pluralidad cultural, conflicto armado y Derecho en el Perú: 1980-1993. Lima: Fondo Editorial de la PUCP. 
GONZÁLES, Raúl. (1988). “La violencia en el Perú". En Diego García (Editor), Democraciay violencia en el Perú. Lima: Centro Peruano de Estudios Internacionales (CEPEI), pp. 19-33.

HATUN WILLAKUY (2008). Versión Abreviada del Informe Final de la Comisión de la Verdad y Reconciliación Perú. Lima: Gráfica Delvi S.R.L.

HEILMAN, Patricia. (2018). Rebeliones inconclusas. Ayacucho antes de Sendero Luminoso, 1985 - 1980. Lima: La Siniestra Ensayos.

LUMBRERAS, Luis. (2006). Violencia y mentalidad colonial en el Perú. Fundamentos para una crítica de la razón colonial. Lima: Instituto Nacional de Cultura-Dirección Regional de Cusco y Universidad Nacional de San Marcos-Fondo Editorial de la Facultad de Ciencias Sociales.

MANRIQUE, Nelson. (2015). El tiempo del miedo. La violencia política en el Perú 1980 - 1996. Lima: Fondo Editorial del Congreso del Perú.

MANSILLA, C. (2000). "La violencia política en el Perú: un esbozo interdisciplinario de interpretación", en Estudios Políticos, Número 25, sexta época.

MCCLINTOCK, César. (1988). "Perspectivas para la consolidación democrática en el Perú". En Diego García (Editor), Democracia y violencia en el Perú. Lima: Centro Peruano de Estudios Internacionales (CEPEI), pp. 35 - 77.

OVIEDO, C. (1989). Prensa y subversión. Una lectura de la violencia política en el Perú. Lima: Mass Comunicación Editores.

PEASE, Franklin. (1999). Breve historia contemporánea del Perú. México: Fondo de Cultura Económica.

PEASE, Henry. (1981). "La constituyente de 1979 en el proceso político peruano". En Perú: Constitución y sociedad política. Lima: Desco - Centro de Estudios y Promoción del Desarrollo, pp. 13 - 54.

PEASE, Henry y ROMERO, G. (2013). La política en el Perú del siglo XX. Lima: Fondo Editorial de la Pontificia Universidad Católica del Perú.

RÉNIQUE, José. (2015). Incendiar la pradera. Un ensayo sobre la revolución en el Perú. Lima: La Siniestra Ensayos.

RUBIO, Marcial. (1986)."Militares y Sendero Luminoso frente al sistema democrático peruano". En Revista de Estudios Políticos (Nueva Época), Número 53, setiembreoctubre.

SÁNCHEZ, M. y J. Ríos (2018). Breve historia de Sendero Luminoso. Madrid - Lima: Catarata y Revuelta Editores. 
SCHNEIDER, Hans. (1991). Democracia y Constitución. Madrid: Centro de Estudios Constitucionales.

TELLO, María. (1989). Sobre el volcán. Diálogo frente a la subversión. Lima: Centro de Estudios Latinoamericanos.

(1991). Perú: el precio de la paz. Lima: Ediciones PETROPERÚ.

TUESTA, Fernando. (1985). El nuevo rostro electoral. Las municipalidades del 83.

Lima: Desco - Centro de Estudios y Promoción del Desarrollo.

UGARTECHE, Óscar. (1999). La arqueología de la modernidad. El Perú entre la globalización y la exclusión. Lima: Desco.

WEBB, Richard. (1999). Una economía muy peruana. Ensayos sobre economía y sociedad. Lima: Congreso de la República.

ZAGREBELSKY, Gustavo. (2008). "La ley, el Derecho y la Constitución". En Jusconstitucional. Análisis multidisciplinario de la jurisprudencia del Tribunal Constitucional. Lima. № 6, Junio, pp. 323 - 335. 


\title{
LA ECOPEDAGOGÍA COMO DERECHO EMERGENTE
}

\section{LA ECOPEDAGOGÍA COMO DERECHO EMERGENTE}

\author{
Yuri Angeles Mercado ${ }^{(1)}$ \\ Universidad Veracruzana, México
}

\begin{abstract}
Resumen: Un derecho emergente que construya la vía para el acceso a derechos humanos como la salud y la justicia, es la educación para una ciudadanía planetaria. La ecopedagogía es un modelo educativo que en su ejercicio conmina a la reflexión y práctica de que busca formar ciudadanos que construyan sociedades donde los sectores vulnerables (mujeres, indígenas y niños) cuenten con la posibilidad de vivir en ambientes ecológicamente sanos, socialmente justos y económicamente equilibrados. Que las escuelas de todos niveles, principalmente las públicas se ocupen de involucrar positivamente a los niños y jóvenes en la resolución de problemas sociales, ambientales y económicos es un grito emergente de la humanidad.
\end{abstract}

Abstract: An emerging right that builds the pathway to access to human rights such as health and justice is education for a planetary citizenship. Ecopedagogy is an educational model that in tehir exercise contends with the reflection and practice of basic elements in real contexts that seeks to form citizens who build societies where vulnerable sectors (women, indigenous and children) have the possibility to live in an environment ecologically healthy, socially just and economically balanced. That schools at all levels, mainly public schools, are responsible for involucrate childrens and youngs in solving social, environmental and economic problems is an emerging cry of humanity.

(1) Ingeniera en Agroecología. Maestrante en Educación para la Interculturalidad y sustentabilidad. Asesora del Instituto de Juventud y Encargada de Cultura Ambiental del Municipio de Puebla 


\section{La mochila de historias que sustentan la petición}

Son las 11:40, es una mañana soleada en el municipio de Cuautinchan en el Estado de Puebla, en el salón de 5to semestre de un bachillerato ubicado a $600 \mathrm{~m}$ de un pequeño río, está por comenzar la clase; en este mismo momento, otro grupo de jóvenes, de otro bachiller del municipio de Venustiano Carranza enclavado en una zona selvática, vecino de inmensos y frondosos cafetales se dispone también a iniciar su clase; la misma imagen de jóvenes animando un salón pero el escenario ahora, es el municipio de Zacatlán, situado justo en el corazón de un bosque ... es hora de la clase de Biología, el profesor después de dar los buenos días indica: "el tema del día es Biodiversidad, por favor, cierren las cortinas, vamos a ver un documental de National Geographic y al terminar discutiremos para que mañana me traigan un ensayo..."

Las aves, los árboles y mezquites, las ardillas, lagartijas, conejos y onzas, se quedan afuera de esas aulas, sobreviviendo al ritmo del progreso, y esperando que esos jóvenes salgan de esas clases magistrales entendiendo que ellos, las comunidades de seres vivos que conviven cada día en el mismo espacio que han habitado sus abuelos y tatarabuelos también son biodiversidad y son tan valiosos como los curiosos osos panda de la China o los canguros australianos...

Otro día, otra escena y escenario... Es una mañana húmeda en verano, de los pocos días en que a pesar de ser un sitio árido hay suficiente humedad para que proliferen los hongos, una pareja de ancianos aprovecha para recolectar ... es la hora de entrada del bachiller en la comunidad de Almoloya en el municipio de Cuautinchan; muchos chicos pasan sin reparar en los ancianos, algunos los ven extrañados, los menos, saludan apresuradamente... La profesora de ecología y sustentabilidad, también coincide en el camino con los ancianos, los observa, después les pregunta con qué fin recolectan aquello...maravillada de lo que escucha, les pide permiso de enviar algunos alumnos a platicar con ellos. Al llegar al salón, indica tomar una libreta y anotar: "¿qué plantas silvestres utilizan y para qué? ¿qué plantas tienen en sus solares y con qué fin? ¿se acuerdan de algún platillo que comieran de pequeños y que hoy ya no se coma? ¿existe alguna planta silvestre o animal que antes abundara y que hoy ya no exista". Los alumnos tendrían que organizarse para ir en parejas a visitar a sus abuelos y hacerles estas preguntas (esta práctica sencilla de salir del plantel para hacer una actividad extramuros de manera sorpresiva sería impensable en una ciudad grande como la ciudad de Puebla por ejemplo) y así lo hicieron... al día siguiente en el salón compartirían lo aprendido.

Los resultados: una lista de 8 plantas silvestres que no conocían, 5 plantas de los solares que no sabían que tenían uso, 2 plantas que ya no hay en los cerros, 3 platillos que ya nadie come, un grupo de jóvenes maravillados por los conocimientos descubiertos, reconectados con sus abuelos y un grupo de abuelos sabios felices por haber podido transmitirles a los más jóvenes los secretos de sus años ... 
Son los albores de la Universidad Intercultural del Estado de Puebla (UIEP), inicia la difusión de las primeras carreras implementadas, Desarrollo Sustentable y Lengua y Cultura, un grupo de profesores entusiastas sale a los bachilleratos de la región a presumir a sus recién paridos programas académicos... los estudiantes de bachillerato decepcionados, preguntaban por qué no había informática, contaduría, comunicación...ellos querían estudiar algo que les diera las posibilidades de salir de manera inmediata de la sierra, de vivir en edificios y tener oficinas y camionetas...fue difícil convencerlos de inscribirse.

Muchos de los primeros licenciados interculturales, llegaron ahí más por falta de opciones que por gusto, en las primeras generaciones el índice de deserción era alto, muy alto ( $46 \%$ anual aún a 7 años de su creación cuando tuve la oportunidad de ser directora de planeación y evaluación) y aunque hoy en día el trabajo de los egresados y nuevos vínculos institucionales y sociales han logrado la consolidación de otras cuatro licenciaturas más y una disminución significativa de la deserción, no se ha logrado su objetivo primordial: arraigar a los jóvenes y detonar desarrollo local y regional, con ello tampoco se ha frenado el deterioro ambiental y cultural de los territorios de la región donde la universidad se asienta.

Estas historias breves, son parte de la mochila de historias que he logrado acumular en mi andar entre escuelas y parcelas de zonas rurales y urbanas, públicas y privadas en mis diferentes papeles y momentos: como alumna, como maestra, como directora y como madre ...

\section{El derecho emergente a una pedagogía enfocada al cuidado de la Tierra y de los seres humanos}

Un derecho emergente que construya la vía para el derecho humano a la salud es la educación para una ciudadanía planetaria. La ecopedagogía, es un modelo pedagógico que en su ejercicio conmina a la reflexión y práctica de elementos básicos para que todos los seres humanos, pero sobre todo los más vulnerables: mujeres, indígenas, niños cuenten con la posibilidad de vivir en contextos ambientalmente sanos, socialmente justos y economicamente equilibrados.

Nuestro medio ambiente, el conjunto de los elementos que permiten la sobrevivencia humana en la Madre Tierra, está cada vez más deteriorado, y pocos han entendido que el deterioro del estado de la naturaleza va en detrimento directo de la calidad de vida de los hombres. Por ello conmino como una petición urgente para el acceso al derecho humano a la salud y una vida digna, a que todos los niños tengan acceso a una ecoformación que poco a poco afinque, apoyada en procesos interculturales, humanitarios, sustentables y justos, las bases para un mejor mundo para todos quienes habitamos esta Tierra. 
Entre días similares a los narrados en párrafos anteriores, comencé hace un par de años a pensar en alguna o algunas formas para hacer que los niños y jóvenes anhelen ser biólogos, ecólogos, antropólogos, no solo ingenieros mecatrónicos o publicistas y más aún que desde cualquier profesión u oficio que les llene el corazón cuiden nuestra casa común, la Tierra.

Antes de las ideas me asaltan muchas preguntas ¿Por qué muchos jóvenes de zonas ricas en biodiversidad y con numerosas posibilidades de desarrollar proyectos comunitarios crecen desdeñando la riqueza de sus ecosistemas? ¿Por qué muchos jóvenes de las zonas rurales anhelan concluir la educación básica para irse de sus comunidades a buscar el éxito en las grandes urbes? ¿Por qué las carreras de áreas biológicas y sociales tienen cada vez menos auge entre los jóvenes? ¿Por qué los jóvenes desconocen el vasto conocimiento ecológico de sus abuelos si día a día conviven con ellos? ¿Cuántas plantas más ya no conocerán los jóvenes que hoy están en las aulas de los bachilleratos y preparatorias ni sus hijos y nietos?

Muchas son las razones de esta "laguna de conocimiento generacional", entre ellas, que le han vendido a los mayores la idea de que sus conocimientos no sirven: la escuela dice que solo la medicina científica es válida y confiable; la FAO y los técnicos de las dependencias proclamaron durante décadas que la buena alimentación se basa únicamente en los huertos de hortaliza (brócoli, zanahoria, coliflor -y otras plantas no endémicas de su región-). Las instituciones han invalidado sus saberes.

El sistema de vida occidental, privilegia la urbanización, centra la calidad de vida en los edificios y oficinas, se habla solo del lado bonito y cómodo de este sistema, poco se exhibe y menos se discute la sobreexplotación de los mantos acuíferos, la insuficiencia alimentaria, la desnutrición, la propagación de monocultivos y su culpa en la infertilidad de los suelos y en la pandemia de cáncer, la proliferación de plagas y enfermedades agrícolas, pérdida de biodiversidad, la extinción de flora y fauna son temas solo de libros de poca circulación, de investigaciones sociales con pocos lectores, poco se ocupan de ello las instituciones, las políticas públicas. Somos sociedades producto del desarraigo, del olvido de los vínculos de respeto y amor.

¿Cómo pedirle a la madre tierra una oportunidad? ¿cómo queremos aprender a salvaguardar los mal llamados recursos naturales si no nos sentimos parte del mismo entramado de vida? ¡¿Cómo le pedimos a las nuevas generaciones que defiendan lo que no conocen, lo que no aman?!

De entre estas preguntas siento urgente, tajante conectar desde pequeños a los niños y jóvenes con la tierra, o quizá lo propio sea decir "no romper 
ni distraer el vínculo que todo niño posee con su biólogo interior" y que los adultos y las instituciones educativas cortamos en aras del orden y la pulcritud.

Los programas educativos actuales, están allanando el camino para que las empresas del fracking, la minería a cielo abierto, las hidroeléctricas envasen los tesoros de nuestras sierras y bosques y vomiten sus venenos sobre los ríos sin que nadie se los impida.

Contextualizar la educación en el medio rural, discutir en las escuelas de las zonas urbanas la degradación ambiental que causa nuestra vida citadina, son demandas legítimas que aluden a la defensa de la vida.

No solo los biólogos, ecólogos, antropólogos y anexas pueden cuidar a la Tierra, toda persona cualquiera que sea su talento y ocupación debe y puede cuidar el delicado ritmo de nuestro planeta y sus ecosistemas. Todos, incluidos los ingenieros en mecatrónica pueden ayudar a cuidar la vida.

Pero por qué tanto en las ciudades como en el campo es aún bajo el porcentaje de personas que se ocupa (y no sólo se preocupa) de cuidar el medio ambiente. Hay una frase que dice nadie ama lo que no conoce, yo le agregaría que lo que no ama y no siente parte de sí mismo, todos conocemos a las flores, hemos escuchado alguna vez en la vida el canto de las aves pero no los amamos porque nadie o muy pocos estamos conscientes de lo importantes que son para nosotros y nosotros para ellos, nosotros disfrutamos de la existencia gracias a muchas de sus funciones, tristemente ellos de nosotros reciben "explotación" término fuerte y egoísta (en mi opinión), nosotros somos peligrosos para la existencia de los ellos que estuvieron antes que nosotros en el camino de la evolución, nosotros exterminamos bosques, desecamos ríos.

Los seres humanos también construimos, sí, construimos enormes edificios y centros comerciales, creamos aviones y naves espaciales, exploramos el espacio exterior pero no hemos logrado tornar el agua salada en agua dulce y potable, no hemos logrado detener la extinción masiva de especies ¿Qué haremos cuando agotemos o envenenemos por completo los mantos acuíferos? ¿Quién se ha ocupado (de nuevo insisto, no solo hay que preocuparse) de hablar de estas cosas con los niños y jóvenes? A nosotros, los adultos del hoy, ¿quién nos enseñó estas cosas?, ¿quién nos provocó estas dudas y cuándo? En un ejercicio rápido, ¿quién de los que me lee pensó en su vínculo con la naturaleza cuando era niño o joven? ¿Quiénes lo pensaron ya por ahí de la universidad o todavía más adelante?

Chomsky en Esteva (2011) postulaba que nuestros padres y abuelos le compraron tanto al sistema la idea de que solo la escuela educa a los niños y jóvenes, que le confirieron toda la confianza y responsabilidad en la labor, no 
se involucraron y autocensuraron sus conocimientos sobre el amor y respeto a la madre tierra, sobre las formas amigables de producir sin químicos, haciendo policultivos, la milpa y el cafetal diversificado y los resultados hoy saltan a la vista.

La Lista Roja de la UICN, que es la fuente más completa de información sobre el riesgo de extinción de especies de plantas, animales y hongos, ahora incluye 85.604 especies, la mayoría de nosotros no alcanzaremos ni a conocerlas antes de que se extingan (UICN, 2016).

En agosto del año 2017 (el día 8 para ser exactos) hemos sobrepasado la capacidad regenerativa de la Tierra. Esta fecha marcó el punto de inflexión entre lo que consumimos y lo que es capaz de regenerar el Planeta cada año, según datos de la Global Footprint Network (GFN), para el análisis de la huella ecológica. De continuar con el ritmo de "desarrollo" (o modelo de consumo actual), la humanidad necesitaría 1.6 planetas para satisfacer su demanda de recursos naturales. El Día de la Sobrecapacidad de la Tierra, implica que la demanda anual de recursos naturales de la población mundial excede lo que la tierra puede regenerar en ese año. Este "déficit ecológico" fundamentalmente se debe a que emitimos más dióxido de carbono a la atmósfera de lo que los océanos y bosques pueden absorber y a que agotamos las pesquerías y talamos los bosques más rápido de lo que se pueden regenerar (WWF, 2017).

El agua dulce y limpia que podemos usar para consumo humano está también en límites cercanos al agotamiento, los hielos polares se están derritiendo y pocos muy pocos están trabajando para revertir todo esto.

\section{La hipótesis}

El arraigo a la Tierra en su sentido ambiental y socio cultural, se fortalece o se rompe en casa y en la escuela desde los años más tiernos de la infancia. Esta ruptura tiene como consecuencia muchos de los problemas socioambientales que hoy tienen al planeta enfermo y ponen en riesgo nuestra propia sobrevivencia como especie.

\subsection{Las formas de enseñar-aprender ecología y algunas posibles respuestas}

La gran mayoría de escuelas en México no cuenta con elementos que propicien el amor a la tierra, son pocas las áreas verdes, menos aún las parcelas escolares o los jardines botánicos y ni qué decir de los programas de ciencias naturales que desde la educación básica nos enseñan a servirnos de la Tierra y no a cuidarla, respetarla y amarla.

Leo los libros de texto gratuito de mis hijos y recuerdo una cita de Ángela Antunes para el prefacio del libro "Pedagogía de la Tierra" de Moacir Gadotti (2000): 
"En la escuela había visto una Tierra tan diferente ... aprendimos que es uno de los nueve planetas que giran en torno al sol y que es una gran esfera rocosa ... su interior es muy caliente y su corteza rica en minerales y vegetales. Los mares y océanos ocupan la mayor parte de su superficie. Los hombres y las mujeres que habitan este planeta son un éxito...construyen todo tipo de máquinas para tierra, aire y agua. Poco me enseñaron de como la Tierra fue dominada, sometida, esclavizada, dividida en países con inmensas y terribles fronteras. No me hablaron de un planeta despedazado, mutilado y estéril por la lógica de un sistema de producción que no ve a la naturaleza como parte de nosotros y que poco se preocupa por su destrucción. No me explicaron la relación entre las precarias condiciones de vida y la política económica industrial y ambiental. Me eximieron con ello de toda responsabilidad en cuanto al desagüe a cielo abierto, a la basura acumulada en las calles. Oí, escribí. Muy poco fue lo que sentí. Menos aun lo que vivencié".

Me leí en ella y vinieron a mi mente las caras de sorpresa e incredulidad de mis primeros alumnos interculturales, sorprendidos al escuchar sobre la sostenibilidad y que tanto, trata de imitar o basarse en los saberes tradicionales, en la certeza y sabiduría de sus abuelos totonacos evidenciada en los cafetales diversificados que se resistieron a tornarlos monocultivos.

\section{Mis primeros pasos conscientes hacia la ecopedagogía}

Con esta carga de dolores e ideales, comencé en 2015 mi proyecto de maestría (en Educación para la interculturalidad y sustentabilidad) en dos bachilleratos de Cuautinchan, un municipio muy cercano a la capital del Estado de Puebla, el cual fue un gran señorío prehispánico y sitio de gran importancia por su ubicación estratégica durante la colonia.

Este otrora próspero municipio, hoy no ofrece prácticamente nada a sus jóvenes, los campos agrícolas están abandonados, la actividad ganadera se limita al traspatio no es una actividad económica que brinde sustento a las familias. La mayoría de los adultos y jóvenes a partir de los 18 años se trasladan diariamente a la ciudad para ganarse la vida como albañiles, obreros y empleados de comercios de mediana talla.

Aunque la migración permanente no es significativa, casi ninguno de los habitantes en edad productiva obtiene sus ingresos dentro del municipio y menos visualizan en su imaginario de futuro su permanencia en él. Los jóvenes que tienen, aunque con mucho esfuerzo, la oportunidad de prepararse en el nivel medio superior, anhelan dejar este lugar para no volver. 
Mayores elementos representativos de esta incongruencia e insensibilidad que me preocupaba, encontré en el programa de biología para quinto semestre de bachillerato al comenzar a preparar mi propuesta de trabajo "ecopedagógico" con los jóvenes.

En el proyecto, intervine, los programas de Biología II (quinto semestre) y Ecología y Sustentabilidad (sexto semestre), con actividades específicamente de refuerzo. Deplorable encuentro lineamientos tan absurdos como que para la unidad de biodiversidad en una zona rica en biodiversidad, se vea en el aula un documental sobre el tema para posteriormente buscar en "fuentes confiables" información de especies en peligro de extinción y dinámicas evolutivas, (de ahí mi relato inicial) ¿por qué no en lugar de correr las ventanas e impedir la luz del sol para ver el ciclo de vida de los elefantes africanos, salen los profesores a caminar con sus estudiantes para dar valor a los zacatuches, lagartijas, felinos, mamilarias y orquídeas y tantas otras especies vegetales y animales de su entorno? ¿por qué las "fuentes confiables" no son sus padres y abuelos, los que llevan más de una generación observando el ritmo de la vida en su comunidad?

Con este programa de estudios, promotor de lo ajeno, la buena voluntad y el honestamente poco entusiasmo inicial de los jóvenes de los dos bachilleratos más grandes del municipio, comencé a intervenir con actividades lúdicas y orientadas al compartir generacional de conocimientos las actividades de las asignaturas del área biológica del último año de bachillerato.

Comencé a tratar de desarrollar estrategias eco pedagógicas como las que postulan Gadotti, Gutiérrez y Zingaretti, Boff y Morin, esa pedagogía que basada en el juego y la convivencia constante y amorosa con la Madre Tierra apuesta por despertar en los niños y jóvenes una "ciudadanía planetaria" que no es otra cosa que "una sociedad que no humille a nada ni a nadie, que ejerza la ciudadanía de manera cotidiana, que participe en la vida colectiva tratando de mejorar las condiciones de la alteridad" (Zingaretti, 2008).

La ciudadanía planetaria es una consecuencia inexcusable de esta percepción generalizada de los seres humanos de vivir en un mundo interconectado. Si Gaia, como afirma Lovelock (1989: 80 y ss), es un sistema complejo que se autorregula de forma inteligente, nosotros, como parte de él, debemos contribuir a su equilibrio dinámico y no al deterioro de sus condiciones que son, finalmente, el requisito de nuestra supervivencia como especie (Novo y Murga, 2010). Esta ciudadanía, es la que quiero ayudar a construir.

\section{El trabajo con los jóvenes de Cuautinchan}

De los chicos que integraban mi grupo de estudio (46 jóvenes de entre 17 a 19 años, originarios del municipio), la gran mayoría se preparaban para el 
ingreso a la educación superior guiándose más por el listado de las carreras mejor pagadas que circulaba en Facebook y las comodidades que les mostraban como la serpiente a Adán y Eva los medios de comunicación que por sus vocaciones y pasiones. Cuando yo les cuestionaba sobre cómo se proyectaban a sí mismos en 5, 10 y 15 años, los imaginarios de futuro incluían viajes, oficinas, coches del año, esposos guapos.

Cinco jovencitas específicamente, debatían con sus familias entre lo que anhelaban ser y lo que les generaría mayores ingresos y por ende -decían sus familias- calidad de vida, una de ellas incluso se matriculó para estudiar química y no antropología como anhelaba porque casi todos en su círculo familiar y social le decían que no tendría de que vivir; otra dudaba entre enfermería y biología, una más entre comunicación y desarrollo sustentable, otras dos entre ingeniería en alimentos o mejor trabajar que tirar el dinero a la basura, un joven entre administración y agronomía.

Después de dos semestres de incitarlos a cuestionar el sistema educativo y económico, de hacerlos jugar en el pasto cada jueves, de instalar un huerto, una parcela y una unidad de producción de huevo de rancho y una jornada municipal por el medio ambiente, estos seis indecisos eligieron la opción de su corazón enfilándose a prepararse en carreras vinculadas con el manejo amoroso de la naturaleza y de los hombres, 3 familias instalaron también su producción de huevo y casi todos me prometieron cuidar la tierra y enseñar a todos los que pudieran a cuidarla, -no sé si lo estarán haciendo en todo momento pero sé que se muchas cosas se movieron en su interior- lo creí ya casi al final de nuestros "encuentros eco pedagógicos" cuando dejaron de preguntar si respondían con el corazón o la cabeza mis preguntas agitadoras.

\section{Lo que reina en las instituciones educativas y sus objetivos hoy}

Recientemente en nuestro estado se invitaba animosamente a que 200 mil jóvenes ingenieros vengan a cubrir la demanda de ingenieros de Audi y las nuevas empresas instaladas tanto en la capital como en el nuevo nodo tecnológico de San José Chiapa, desde luego es "positivo" a simple vista el hecho de la creación de empleos pero aquí viene el cuestionamiento incomodo de mi sentipensar: ¿por qué no se impulsó y fortaleció la vocación agrícola y agroindustrial de la región de San José Chiapa en lugar de volverla el sillicon valley poblano? ¿de verdad esos jóvenes ingenieros tendrán sueldos y prestaciones de ley que les permitan calidad de vida? ¿qué implican para los impulsores de este tipo de desarrollo el bienestar y la calidad de vida? ¿no era opción empoderar a la región desde su vocación original para que no solo los jóvenes ingenieros sino también los viejos campesinos tuvieran ingresos para sostenerse dignamente? ¿el impacto ambiental de estas empresas de verdad será mitigado en el corto plazo? 
Es alarmante desde mi punto de vista, como tantas vueltas al sol después de que Marx postuló que el capitalismo creó a la educación como el aparato que moldearía a la gente bajo normas prescritas por él, para incorporarlo al mercado de trabajo bajo sus específicas condiciones, sometiéndose a su régimen de trabajo y modo de vida; la fórmula de este sistema educativo y su paradigma siga vigente.

Chomsky señala también al respecto, que para México, la escuela ha tenido la misma vocación que en el viejo continente, la educación y la policía como los dos instrumentos principales en la construcción de los Estados nacionales y así lo es lamentablemente para el mas de $70 \%$ de población que vive sin estabilidad económica y social en nuestro país, sin capacidad de maniobra para cambiar su situación por más que en ello se empeñen, nuestro sistema funciona, funciona como una maquinaria perfecta para quienes lo idearon y sus herederos que lo lideran.

Desde mi locus de enunciación, he visto que la educación en su marco general ha sido la horma por la cual se ha "modelado" una ciudadanía de "características específicas" acordes a cada grupo político en turno, puesto que es el aparato político en el poder quien se encarga de los contenidos curriculares, es decir, que se enseña sólo a lo que a sus intereses conviene, es juez y árbitro en decidir qué se aprenda y qué no. Los grupos políticos en sus diferentes turnos al poder, ostentan la legitimidad de omitir datos e incluso desechar asignaturas completas si las consideran no afines o útiles a sus objetivos, así como de impulsar modelos educativos, sean o no, acordes culturalmente a nuestro país y regiones.

\section{Más pistas sobre la anti pedagogía ecológica}

A casi un año de concluido el proyecto con los jóvenes de Cuautinchan y después de electrizarme con el discurso de los 200 mil ingenieros, realicé, aprovechando el vínculo profesional y afectivo que el programa de liderazgo para jóvenes indígenas de la UDLAP y la Embajada de los Estados Unidos de Norteamérica me han permitido con jóvenes de distintos puntos geográficos y culturales, una encuesta para tener más elementos de juicio sobre mi hipótesis de que la educación formal que se brinda en las escuelas no propicia el vínculo responsable y crítico de los niños y jóvenes hacia la Madre Tierra y que esto, tiene como consecuencia muchos de los problemas socioambientales que hoy la tienen enferma y ponen en riesgo nuestra propia sobrevivencia como especie.

La muestra consistió en 84 personas, de las cuales una vive en Francia, una en Panamá, una en Perú, una en Guatemala, dos en España, dos en Estados Unidos, cinco en Ecuador y 71 en México (pertenecientes a 14 estados y 19 municipios diferentes); las edades van desde los 13 a los 54 años, que aunque no están representados de manera equitativa, son una muestra pequeña pero significativa 
de cómo las formas de enseñanza-aprendizaje de la ecología de una generación a otra, han tenido nula evolución y han formado ciudadanos poco preocupados por la Tierra, así como también aportan una idea clara de cosas que hace falta hacer y fomentar para revirar el camino de la sociedad homocéntrica hacia una ecocéntrica.

Fue revelador y reconfortante que más del $80 \%$ de los encuestados propone que la ecología "se viva" y no solo se lea o se observe en una pantalla. Proponen huertos, viveros y jardines botánicos, proponen viajes temáticos enfocados al conocimiento de la naturaleza y la escucha de los más viejos, ya que carecieron de estos espacios y experiencias en su infancia y juventud, y los consideran hoy, estrategias a seguir para que el arraigo a la Casa Común como la llama Boff, se erija como un nuevo paradigma de existencia justa para todos los que la habitamos.

\section{La propuesta/contrapropuesta}

Ante este panorama de desigualdad, pero a la vez de esperanza inflamada por jóvenes que despiertan del letargo y se organizan para darle la mano al prójimo, que proponen que "el compromiso social" sea una asignatura obligatoria que se imparta desde los primeros grados escolares, apuesto aún más a la práctica cotidiana de la ecopedagogía, al fortalecimiento del vínculo amoroso que todos los seres humanos traemos de nacimiento.

Propongo la creación de más áreas verdes en las escuelas y las calles, propongo la convivencia intergeneracional respetuosa y el diálogo de saberes como generadores de conocimiento, propongo más ecología divertida y productiva en las escuelas, propongo huertos escolares y jardines botánicos, que los niños cosechen sus alimentos para que saboreen distinto los vegetales, para enamorarlos de la naturaleza y llevar la ética del amor y el cuidado consigo a todas partes.

Propongo que los "Derechos naturales de los niños" que Gianfranco Zavalloni comienza a compilar en Italia y que Rubem Alves retoma en Brasil, sean un decálogo a seguir por las familias y escuelas de formación básica públicas y privadas, decálogo que defiende:

1. El derecho al ocio. Períodos de tiempo que no estén planificados por los adultos, tiempo para distraerse.

2. El derecho de ensuciarse. Jugar con la arena, la tierra, la hierba, las hojas, las piedras, el agua, hacer barro.

3. El derecho de oler. Sentir el placer del olor, reconocer los aromas de la naturaleza, de las comidas. 
4. El derecho al diálogo. Tener la oportunidad de hablar, de ser escuchado y también de escuchar a los demás.

5. El derecho a utilizar las manos. Utilizar el papel de lija, encolar, modelar barro, ligar cuerdas, usar el tacto para reconocer los materiales.

6. El derecho a un buen comienzo. Tomar alimentos sanos desde el nacimiento, beber agua fresca y respirar aire puro.

7. El derecho a la calle. Jugar libremente en la plaza, caminar por la calle, poder disfrutar de los pueblos y de las ciudades.

8. El derecho a lo salvaje. Construir una cabaña en el bosque, jugar al escondite entre las cañas y trepar a los a árboles, bañarse en los ríos, saltar desde lo alto, caer y levantarse de nuevo.

9. El derecho al silencio. Sentir soplar el viento, el cantar los pájaros, el borboteo del agua, el rumor de un bosque, la calma.

10. El derechos a los matices. A ver el amanecer y el ocaso y admirar por la noche la luna y las estrellas.

Sin duda para que estos Derechos sean disfrutados por nuestros niños hay mucho trabajo por hacer más allá de las aulas, entre ello recuperar la seguridad y la paz positiva, una paz verdadera basada en la justicia, pero estoy segura que las generaciones de niños y jóvenes que gocen de estos derechos y experiencias, se formarán desde aprendizajes significativos y serán ciudadanos planetarios, responsables de sí mismos, de su madre la Tierra y de sus hermanos los hombres.

\section{Bibliografía}

BOFF, Leonardo. 2017. La casa común, la espiritualidad, el amor. México, Ediciones Dabar.

ELORZA MORALES, Miguel Ángel. 2013. Educación libertaria y comunalidad. México, Colegio de Investigadores en Educación de Oaxaca S.C. / CIPO-RFM.

GADOTTI, Moacir. 2002. Pedagogía de la Tierra. México-Argentina, Editorial Siglo XXI.

NOVO, María y Murga, Angeles. 2010. Educación ambiental y ciudadanía planetaria. Rev. Eureka Enseñ. Divul. Cien., No7 Extraordinario, pp. 179-186. España, Universidad de Cádiz. 
UICN, Unión Internacional para la Conservación de la Naturaleza. 2016, Informe anual.

ZINGARETTI, Humberto. 2008. La ecopedagogía y la formación de los niños. En X Congreso Nacional y II Congreso Internacional "REPENSAR LA NIÑEZ EN EL SIGLO XXI". Universidad Nacional de Cuyo, Argentina. 


\title{
CONSEJO EDITORIAL
}

\author{
REVISTA DE LA FACULTAD DE DERECHO Y CIENCIAS POLÍTICAS \\ Universidad Nacional de San Antonio Abad del Cusco \\ Año LXXI - No 11 \\ CUARTA ÉPOCA \\ 2019
}

PÁVEL HUMBERTO VALER BELLOTA (Doctor)

Universidad Nacional de San Antonio Abad del Cusco, Perú

JORGE POLO Y LA BORDA GONZALES (Doctor)

Universidad Nacional de San Antonio Abad del Cusco, Perú

JOSÉ BÉJAR QUISPE (Doctor)

Universidad Nacional de San Antonio Abad del Cusco, Perú

WILBERT BUSTAMANTE DEL CASTILLO (Magister)

Universidad Nacional de San Antonio Abad del Cusco, Perú

MARCO MARROQUÍN MUÑIZ (Magister)

Universidad Nacional de San Antonio Abad del Cusco, Perú

ERNESTO LECHUGA PINO (Magister)

Universidad San Martín de Porres, Perú

MARÍA CANDELARIA QUISPE PONCE (Doctora)

Universidad Nacional Mayor de San Marcos, Perú

Tribunal Constitucional del Perú. Centro de Estudios Constitucionales

JOSÉ MANUEL MAYORGA ZÁRATE (Magister)

Ministerio Público, Perú

LISBETH NÚÑEZ ANDÍA (Magister)

Ministerio de la Mujer y Poblaciones Vulnerables, Perú 
MYRIAM E. YATACO CAVILO (Magister)

New York University, EUA

Universidad Nacional Mayor de San Marcos, Perú

ANTONIO CARLOS WOLKMER (Doctor)

Universidade La Salle, Brasil

PATRICIA GÓMEZ (Magister)

Universidad de Buenos Aires, Argentina

MARKONI GONZALES PICHIGUA (Magister)

Universidad de Paris 13, Francia

JUANA DEL CARPIO DELGADO (Doctora)

Universidad Pablo de Olavide, España

FRANCISCO LETAMENDÍA BELZUNCE (Doctor)

Universidad del País Vasco, España

FRANCISCO JAVIER CABALLERO HARRIET (Doctor)

Universidad del País Vasco, España

HUGO ENRIQUE ORTIZ PILARES (Doctor)

Universidad de Alicante, España 


\title{
FACULTAD DE DERECHO Y CIENCIAS POLÍTICAS ESCUELA PROFESIONAL DE DERECHO Universidad Nacional de San Antonio Abad del Cusco
}

\author{
Decano de la Facultad de Derecho y Ciencias Sociales
}

José Bejar Quispe

Director de la Escuela Profesional de Derecho

Marco Antonio Marroquín Muñiz

Director del Departamento Académico de Derecho

Jorge Polo y La Borda Gonzales

Docentes nombrados

Alfredo Fernández Ttito

Carlos Quispe Álvarez

Dariberto Palma Barreda

Darwin Alex Somocurcio Pacheco

Edith Chuquimia Hurtado

Elías Julio Carreño Peralta

Guido Muelle Villena

Jorge Polo y La Borda Gonzales

José Béjar Quispe

Juan Enrique Torre Rueda

Liliana Luna Zúñiga

Marco Antonio Marroquín Muñiz

Miriam Helly Pinares Silva

Pável Humberto Valer Bellota

Pedro Crisólogo Aldea Suyo

Silvia Elena Aguirre Abarca

Víctor Germán Boluarte Medina

Walter Heraclio Sarmiento Enciso

Wilbert Bustamante del Castillo

Wilfredo Uscamayta Carrasco 


\section{Docentes contratados}

Cerafina Antonieta Zuñiga Leva

Clorinda Pozo Roldán

Eduardo Carlos Jayo Silva

Edward Joseph Aranzabal Delgado

Elvis Oroz Figueroa

Ericson Delgado Otazú

Guido Rodríguez Cárdenas

Jenny Elizabeth Suca Lima

Jim Franz Chevarria Montesinos

José Luís Zambrano López

Juanita Soledad Holgado Quehuarucho

Katherin Fanny Latorre Acurio

Lizbeth Nohemí Yépez Provincia

Luís Ángel Aragón Carreño

Marco Antonio Abarca Alfaro

Marleny Concha Pérez

Miguel Ángel Bravo Miranda

Ney Alencastre Álvarez

Patricia Guillén Vera

Raul Jorge Arce Zans

Rodrigo Uscamayta Ortiz de Zevallos

Rosali Palermo Matos Oliva

Roxana Vizcardo Villalba

Yeny Marleny Olivares Tapia

Yolanda Yunguri Fernández

Yovanh Mendoza Gamboa

Yunder Labra Corrales

Zynthia Gastañaga Rodríguez

\section{Centro Federado de Estudiantes de Derecho}

Roberto Alexis Miranda Chanco (Presidente)

Douglas Andy Sinche Huaman ( $1^{\circ}$ Vicepresidente)

Alison Huachaca Aedo ( $2^{\circ}$ Vicepresidenta)

Vanesa Escobar Marcavillaca (Comisión de Publicaciones)

\section{Estudiantes Representantes ante los Órganos de Gobierno Universitario}

Evelyn Guillermina Castro Coaboy (Asamblea Universitaria)

Ybeth Corrales Achahuanco (Consejo Universitario)

Rudy Quispe Cárdenas (Consejo de Facultad)

\section{Personal administrativo}

Judith Baca Loaiza (Asistente Administrativa)

Lilian Corrales García (Biblioteca)

Valentín Quentasi de la Cruz (Mesa de Partes)

Demetrio Salas Aguilar (Mantenimiento) 